\title{
Energy restriction and potential energy restriction mimetics
}

\author{
Sibylle Nikolai*, Kathrin Pallauf, Patricia Huebbe and Gerald Rimbach \\ Institute of Human Nutrition and Food Science, University of Kiel, Kiel, Germany
}

\section{Abstract}

Energy restriction (ER; also known as caloric restriction) is the only nutritional intervention that has repeatedly been shown to increase lifespan in model organisms and may delay ageing in humans. In the present review we discuss current scientific literature on ER and its molecular, metabolic and hormonal effects. Moreover, criteria for the classification of substances that might induce positive ER-like changes without having to reduce energy intake are summarised. Additionally, the putative ER mimetics (ERM) 2-deoxy-D-glucose, metformin, rapamycin, resveratrol, spermidine and lipoic acid and their suggested molecular targets are discussed. While there are reports on these ERM candidates that describe lifespan extension in model organisms, data on longevity-inducing effects in higher organisms such as mice remain controversial or are missing. Furthermore, some of these candidates produce detrimental side effects such as immunosuppression or lactic acidosis, or have not been tested for safety in long-term studies. Up to now, there are no known ERM that could be recommended without limitations for use in humans.

\section{Key words: Energy restriction: Energy restriction mimetics: Healthy ageing: Longevity: Lifespan}

\section{Introduction}

Overweight and obesity are emerging problems all over the world - not only developed countries but also recently industrialised and developing countries are struggling under the burden of this epidemic ${ }^{(1)}$. In Germany, one in five adults suffers from severe obesity, indicated by a BMI of $30 \mathrm{~kg} / \mathrm{m}^{2}$ or higher $^{(2)}$ and even $60 \%$ of German adults are overweight (i.e. with a BMI of $25 \mathrm{~kg} / \mathrm{m}^{2}$ or higher) ${ }^{(3)}$. Apart from limitations in everyday life such as impaired physical performance or dyspnoea caused by obesity, the incidence of associated disorders severely increases the more body weight is gained ${ }^{(4-6)}$. In the past, chronic diseases like type 2 diabetes mellitus (T2DM), hypertension, CVD and cancer were mostly observed in the elderly. Nowadays, many young individuals are also constrained by these pathologies because of excess weight ${ }^{(7)}$. It is estimated that the worldwide mortality from chronic diseases will increase up to $66 \%$ in $2030^{(1)}$. For this reason, food and health agencies such as the USDA (United States Department of Health and Human Services and United States Department of Agriculture) recommend choosing foods high in vitamins and minerals but low (to moderate) in energy density in order to decrease the risk of such diet-related diseases. Indeed, by changing Western eating patterns, enhancing physical activity levels and avoiding tobacco use, the risk of CVD and T2DM as well as of cancer could be reduced by 80 and $40 \%$, respectively $^{(1)}$.
It has been hypothesised that ageing and its associated diseases may be the result of increasing amounts of altered nuclear and mitochondrial DNA, structurally aberrant proteins, and oxidised lipids that lead to structural and functional impairment of single cells and whole organisms ${ }^{(8,9)}$. This may impede dealing with and recovering from endogenous and environmental stress, thereby favouring the development of age-related chronic diseases ${ }^{(10,11)}$.

In the following, current literature on energy restriction (ER; also known as caloric restriction), the most promising method to counteract obesity and ageing, and on its underlying mechanisms such as anti-inflammatory and antioxidant effects is reviewed. Additionally, substances that have been discussed as potentially mimicking ER are also discussed.

\section{Energy restriction and lifespan in model organisms}

$\mathrm{ER}$, a reduction in energy intake of $20 \%$ (mild ER) to $50 \%$ (severe ER $^{(12,13)}$ without a reduction in essential nutrients or malnutrition $^{(14)}$, was shown to reduce obesity and prevent premature onset of chronic ageing-associated diseases ${ }^{(15)}$. Up to now ER is the only intervention which reliably increases lifespan in various model organisms ${ }^{(10)}$.

In an early study in 1935, rats on a hypoenergetic diet showed increased lifespan ${ }^{(16)}$. Since then several studies have

Abbreviations: 2DG, 2-deoxy-d-glucose; AMPK, AMP-activated protein kinase; ER, energy restriction; ERM, energy restriction mimetic; FOXO, forkhead box O; GH, growth hormone; IGF-1, insulin-like growth factor 1; mTOR, mammalian target of rapamycin; mTORC1, mammalian target of rapamycin complex 1; NIA, United States National Institute on Aging; Nrf2, nuclear factor (erythroid-derived 2) like 2; p-AMPK, phosphorylated AMPK; PGC1 $\alpha$, PPAR $\gamma$ coactivator 1- $\alpha$; ROS, reactive oxygen species; RSV, resveratrol; SIRT, sirtuin; SOD, superoxide dismutase; SPD, spermidine; T2DM, type 2 diabetes mellitus; UCP, uncoupling protein.

* Corresponding author: Sibylle Nikolai, fax +49 431880 2628, email nikolai@foodsci.uni-kiel.de 
verified these findings in model organisms extending from yeast ${ }^{(17)}$ over invertebrate species like Caenorhabditis elegans $^{(18)}$ and Drosophila melanogaster ${ }^{(19)}$ to rodents and primates $^{(20-22)}$. Conversely, there are reports that ER may also shorten lifespan in mammals ${ }^{(23)}$ and a meta-analysis by Swindell ${ }^{(24)}$ concluded that the ER-induced lifespan increase in rodents depended on the genotype. Furthermore, it is questionable whether ad libitum-fed animals are the adequate controls for ER studies because ad libitum intake can lead to overweight and consequently shorten lifespan ${ }^{(25)}$. In contrast to an earlier study in rhesus monkeys at the Wisconsin National Primate Research Center ${ }^{(22)}$, Mattison et al. ${ }^{(26)}$ found, on the one hand, that ER did not affect the animals' lifespan. On the other hand, the ER-fed monkeys showed a later onset of age-related diseases than the ad libitum-fed controls and therefore an increased healthspan.

In the Biosphere 2 study in the early 1990s a small number of human subjects unintentionally had limited access to food for about 2 years. Being sealed into a materially closed ecosystem these human subjects were farming and processing their own food, resulting in an energy-limited but nutrient-dense diet. This ER of up to $30 \%$ led to phenotypes similar to those known from ER studies in model organisms ${ }^{(27-29)}$. As with rodents and primates, the human subjects displayed decreased body weight and temperature, lowered fasting glucose and insulin levels, and reduced BMR and blood pressure compared with before the study ${ }^{(27,29)}$. A $25 \%$ reduction in energy intake for 6 months in the statistically high-powered CALERIE (Comprehensive Assessment of the Long-term Effects of Reducing Intake of
Energy) study by the United States National Institute on Aging (NIA) showed results consistent with these findings. Although there are few data on ER in humans, it is known that the inhabitants of Okinawa Island traditionally consumed a modified Japanese diet containing about $20 \%$ less energy than the Western high-fat diet. Interestingly, the number of centenarians in this population is 4- to 5-fold higher than in Western populations and the Okinawan life expectancy is the highest in the world $^{(30)}$. However, in the Okinawan population aged under 65 years, there seems to be a trend towards a lower life expectancy compared with the older generation. This is most probably due to a change from traditional dietary patterns to energy-dense Western-type diets that was initiated in the $1960 \mathrm{~s}^{(31)}$.

\section{Physical appearance during energy restriction}

In addition to a reduction in body weight and fat content ${ }^{(22,32)}$, body temperature also decreases under $\mathrm{ER}^{(33,34)}$. In model organisms on a lifelong ER, a decline in growth and delayed sexual maturity occurred ${ }^{(34)}$ possibly resulting in reduced reproduction rates. In these hypoenergetic-fed animals, a shift from development and reproduction towards maintenance can be observed. Interestingly, changes in activity levels upon ER feeding seem to be species dependent. While rodents undergoing ER showed higher activity levels than ad libitum-fed controls $^{(35)}$, primates displayed mostly unchanged activity patterns compared with the controls ${ }^{(32,34)}$.

Fig. 1 summarises some of the suggested targets that energy restriction might address.

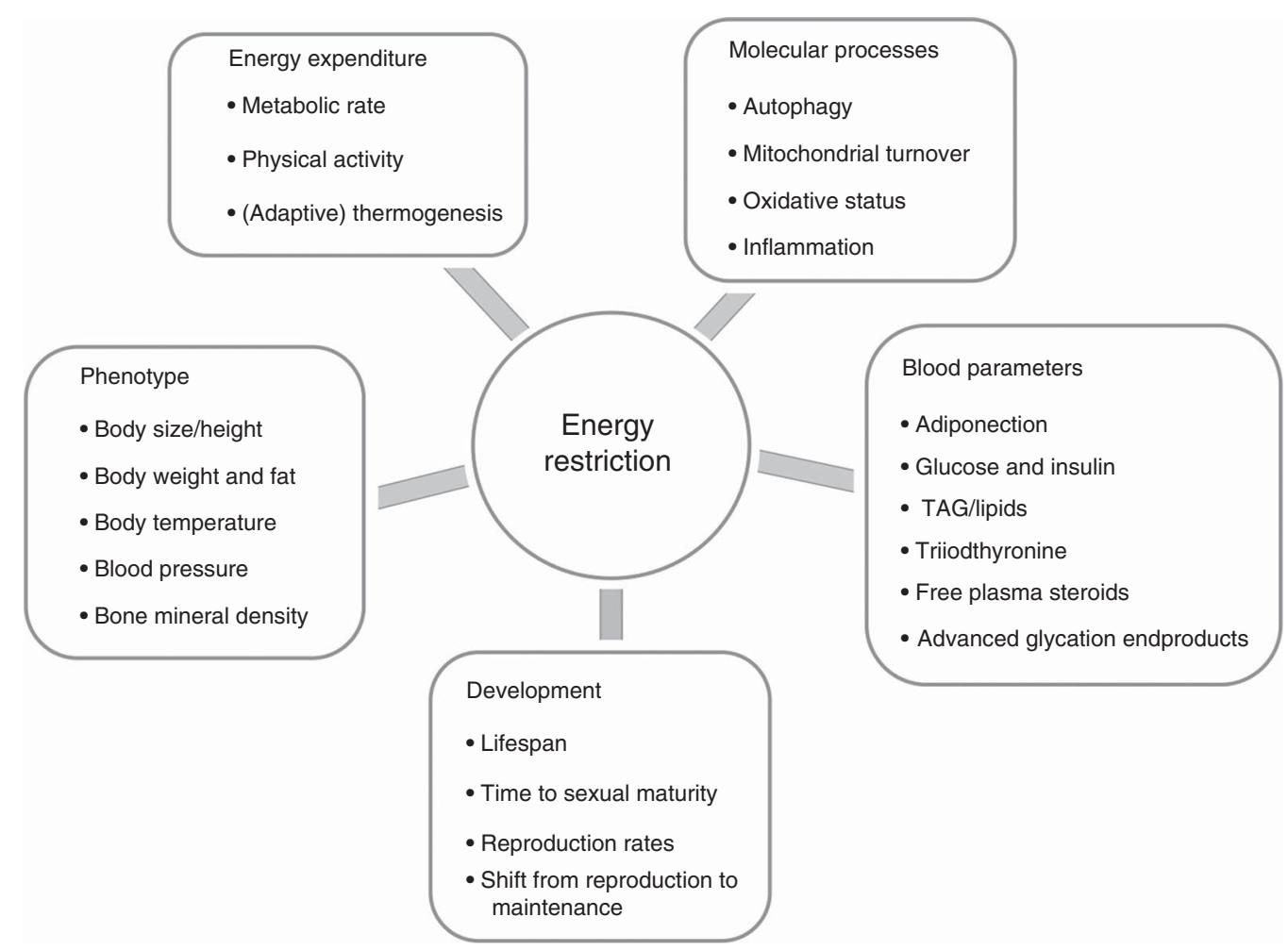

Fig. 1. Schematic overview of the suggested targets that energy restriction might address. 


\section{Blood parameters during energy restriction}

As expected from epidemiological studies, in rodent models reduced body weight in the ER groups was accompanied by a decreased risk of developing age-related diseases such as $\mathrm{T}_{2} \mathrm{DM}^{(36)}$. In initially overweight as well as in normal-weight subjects, fasting plasma glucose and insulin were reduced ${ }^{(37,38)}$ whereas adiponectin levels ${ }^{(39)}$ and insulin sensitivity increased ${ }^{(40)}$ upon energy restriction. Interestingly, consuming energyrestricted diets even reversed existing diabetic changes like insulin resistance ${ }^{(41)}$. ER regimens were also seen to attenuate hypertension $^{(42)}$ and hyperlipidaemia ${ }^{(43)}$. The latter observation might also be due to changes in nutrient utilisation. Since, in order to compensate for reduced glucose intake upon ER, gluconeogenesis from lipids and amino acids is induced ${ }^{(44)}$. In contrast, as shown in rats, glycolysis is reduced under $\mathrm{ER}^{(45)}$.

Moreover, improved glucoregulation reduces glycation reactions, in which blood glucose molecules react with amino acids, proteins or nucleic acids in Maillard reactions to form advanced glycation endproducts (AGE) ${ }^{(46)}$. These can bind to their receptors (receptors for AGE; RAGE) in various tissues, thereby inducing renal, vascular or neurological changes that are observed in ageing-related pathologies ${ }^{(40,47)}$. Thus, reducing blood glucose levels via ER might contribute to lowering the risk of developing age-dependent diseases such as CVD $^{(48)}$, neurodegenerative diseases ${ }^{(49)}$ and cancer ${ }^{(50,51)}$.

While insulin secretion is decreased, plasma concentrations of glucocorticoids usually increase when food intake is limited $^{(52)}$. As to be expected from reduced growing rates and the slowing down of maturation, levels of anabolic hormones like leptin and insulin, testosterone, oestradiol ${ }^{(53)}$ and folliclestimulating hormone ${ }^{(32)}$ decreased upon ER in several species. However, changes in levels of steroid hormones seem to be dependent on the species, as no changes were seen in primates. In contrast, plasma concentrations of the catabolic adiponectin $^{(39)}$ and of the steroid hormone-binding protein ${ }^{(54)}$ tend to be increased by ER. Probably, increased steroid hormonebinding protein levels contribute to the reduced availability of gonadal steroids like testosterone and oestradiol as observed in human subjects undergoing ER regimens ${ }^{(55,56)}$. Similar to leptin, insulin and testosterone, triiodothyronine (T3) consistently declined in rodents ${ }^{(57)}$, primates ${ }^{(58)}$ and human subjects ${ }^{(28,59,60)}$ upon ER feeding. Remarkably, reduced T3 levels fit well with the reduced body temperatures of ER-fed subjects, as the positive correlation of $\mathrm{T} 3$ and body temperature has been known for several years ${ }^{(61)}$. In dwarf mice a deficiency in thyroid-stimulating hormone resulted in hypothyroidism ${ }^{(62)}$ which causes decreased T3 levels. These mice had increased lifespans that were probably mediated by reduced metabolic rates ${ }^{(62)}$ and a subsequent reduction in the generation of reactive oxygen species (ROS). However, adaptive thermogenesis might be increased upon ER, as mRNA and protein concentrations of its main regulators uncoupling proteins (UCP) were increased in skeletal muscle of mice ${ }^{(63,64)}$. Because of the increased energy utilisation for mitochondrial heat production as mediated by increased UCP signalling - ROS production ${ }^{(65)}$ and the resulting oxidative damage could potentially be decreased.

\section{Cellular processes affected by energy restriction}

\section{Energy restriction and oxidative status}

Recently, an increasing number of researchers have become interested in the hormesis effect on healthy ageing ${ }^{(66)}$. This phenomenon describes how a low dose of a stimulus (for example, ROS) induces a positive effect and a high dose of the same stimulus induces a negative effect ${ }^{(67)}$. As far as ER is concerned, limiting energy supply can be seen as a factor causing mild stress in an organism which activates mechanisms of endogenous stress response, thereby improving the overall protection against stress ${ }^{(68,69)}$. Consistently, enhanced expression of heat shock proteins and antioxidant enzymes under ER support this hypothesis ${ }^{(70)}$. Since accumulated stress is observed in age-related disease, ER might enhance healthspan and lifespan via hormesis ${ }^{(68)}$.

Although oxidative damage accumulates during ageing ${ }^{(71)}$ and is characteristic of age-related diseases such as $\mathrm{CVD}^{(72)}$, cancer $^{(73)}$ and neurodegenerative pathologies ${ }^{(74,75)}$, it is not known whether increased ROS levels are the cause or a consequence of ageing.

ER is assumed to alleviate the age-associated increase in oxidative stress ${ }^{(57,76)}$, probably via improving endogenous stress response mechanisms ${ }^{(40)}$ including several redox-sensitive transcription factors. Indeed, in mice undergoing ER antioxidant enzymes under the transcriptional control of the redox-sensitive transcription factor nuclear factor (erythroid-derived 2) like 2 (Nrf2) such as NQO1 (NAD(P)H dehydrogenase, quinone 1) ${ }^{(77)}$ were induced.

Nrf2 protects the organism from the harmful effects of oxidative stress $^{(78)}$. Nrf2 transactivates the expression of genes encoding enzymes that may prevent oxidative damage to cellular structures or remove damaged molecules ${ }^{(79)}$. Apart from NQO1, Nrf2 also induces the transcription of phase II enzymes like glutathione $S$-transferases in mice ${ }^{(78)}$. Moreover, Nrf2 knock-out mice showed decreased expressions of the antioxidant enzymes catalase, haeme oxygenase 1 (HO1) and superoxide dismutase (SOD) $1^{(80)}$. By stimulating proteasomal degradation, Nrf2 can further reduce the burden of oxidatively damaged macromolecules ${ }^{(81)}$. Interestingly, the expression and transcriptional activity of Nrf2 were shown to decline in tissues of ageing rodents ${ }^{(82,83)}$ and ER was shown to enhance the activity of Nrf2. In mice under ER several Nrf2 target genes were up-regulated, which protected these mice from tumorigenesis. However, this anti-cancer effect was diminished in Nrf2 knockout mice ${ }^{(84)}$, suggesting a contribution of Nrf2 to the healthpromoting effects induced by $\mathrm{ER}^{(85)}$. Additionally, oxidative damage to macromolecules seems to be reduced upon $\mathrm{ER}^{(76)}$, but these beneficial effects often occur only after several months of $\mathrm{ER}^{(86)}$.

However, in lifespan studies, mutants expressing higher levels of antioxidant enzymes did not always live longer than the controls. While a SOD1 knock-out decreased lifespan in mice ${ }^{(87)}$, higher activity of SOD1 (CuZnSOD) did not promote longevity in mice ${ }^{(88)}$. Although higher levels of oxidative damaged DNA could be detected in animals with reduced SOD2 (MnSOD) activity, a SOD2 knock-out trial did not reveal different lifespans in transgenic $v$. control mice ${ }^{(89)}$. Similarly, supplementing mice with 
antioxidants like glutathione ${ }^{(90)}$, vitamin $\mathrm{C}^{(91)}$, lipoic acid or coenzyme Q10 ${ }^{(92)}$ did not increase lifespan compared with the untreated controls.

However, in the case of catalase, overexpression of this antioxidant enzyme extended lifespan in mice ${ }^{(93)}$.

\section{Energy restriction and inflammation}

While Nrf2, which is thought to be protective against agerelated diseases ${ }^{(85)}$, was shown to decrease with age ${ }^{(82,83)}$ the transcription factors NF- $\mathrm{KB}$, activator protein- 1 and hypoxia inducible factor- 1 were shown to be up-regulated age-dependently and in the presence of $\operatorname{ROS}^{(10)}$. When activated, they contribute to the development of inflammation and associated disorders, for example, arthritis ${ }^{(94)}$, cancer, atherosclerosis or neurodegenerative diseases ${ }^{(95,96)}$.

$\mathrm{NF}-\mathrm{\kappa B}$ leads to the expression of pro-inflammatory genes encoding cytokines, chemokines and inflammatory cell adhesion which in turn worsen the ROS overload and further promote the activity of $\mathrm{NF}-\kappa \mathrm{B}^{(97)}$. ER consistently decreased the transcriptional activity of $\mathrm{NF}-\kappa \mathrm{B}$ and hypoxia inducible factor- ${ }^{(98-100)}$. However, the precise mechanism of how ROS increases the activity of these transcription factors is largely unknown $^{(10,101)}$. Most likely the reduced load of ROS contributes to a well-balanced cellular redox state, thereby potentially preventing the development of disadvantageous age-associated pathologies ${ }^{(10)}$.

Inflammation increases with age ${ }^{(102)}$ and body weight ${ }^{(103)}$ and is often related to tissue injury, organ dysfunction, fibrosis, several chronic diseases and ageing in general ${ }^{(104)}$.

ER increased the anti-inflammatory hormones adiponectin, ghrelin and corticosteroids ${ }^{(66)}$ and PPAR transcription factors as well as NF- $\kappa B$ inhibitor $\alpha^{(105,106)}$ in the plasma of human subjects and rodents. In contrast, NF- $\kappa \mathrm{B}$ targets such as inflammation-promoting $\mathrm{PG}$, thromboxanes and other cytokines (TNF $\alpha$, IL-6, inducible NO synthase, vascular cell adhesion molecule and intercellular adhesion molecule) were decreased ${ }^{(32,99,107,108)}$. In line with these findings, a diet rich in fat and sugar may increase systemic inflammation ${ }^{(7)}$.

\section{Energy restriction and mitochondrial metabolism}

The cellular energy suppliers mitochondria are very sensitive to oxidative damage and are a considerable ROS source themselves ${ }^{(109)}$. Most importantly, these double-membraned organelles contain a subset of different proteins that generate ATP as an energy source for the organism. However, in the oxidation steps of the mitochondrial electron chain, superoxide radicals are formed from leaking electrons and molecular oxygen $^{(110,111)}$. Leakage of electrons and therefore basal ROS production increases once the mitochondria become old ${ }^{(109,112,113)}$ and decreased efficiency in mitochondrial ATP production during ageing leads to less energy and more $\operatorname{ROS}^{(114)}$, which in turn further damages mitochondria. Similar to other antioxidant defence mechanisms, the activity of the mitochondrial antioxidant defence enzyme SOD2 (MnSOD) also declines with increasing age ${ }^{(115)}$, thereby favouring the vicious cycle of less efficient enzymes in the mitochondrial respiratory chain. That leads to an increase in oxidative stress resulting in further mitochondrial destruction.

Thus, it seems useful to promote mitochondrial turnover by enhancing biogenesis of new mitochondria and degradation of old and damaged ones. Biogenesis of mitochondria is a complex multistep interplay of various transcripts and proteins with nuclear, cytosolic and mitochondrial origin ${ }^{(116)}$. It may be activated in response to different stimuli like nutrient supply, endocrine signals, growth factors and changes in temperature $^{(117)}$. PPAR $\gamma$ coactivator $1 \alpha$ (PGC1 $\left.\alpha\right)$ is thought to be the key modulator of mitochondrial biogenesis and function, as it regulates the activity of other important factors in mitochondrial biogenesis like nuclear respiratory factors 1 and 2 and oestrogen-related receptors $^{(118)}$. In turn, nuclear respiratory factors 1 and 2 may induce mitochondrial transcription factor A, which is essential in controlling the expression of mitochondrial genes $^{(119)}$. Oestrogen-related receptors target genes are thought to be involved in nutrient-degrading processes, oxidative phosphorylation and mitochondrial dynamics ${ }^{(118)}$.

ER was shown to induce mitochondrial biogenesis by enhancing the expression of $\mathrm{PGC} 1 \alpha$ and nuclear respiratory factor 1 as well as their downstream target mitochondrial transcription factor $\mathrm{A}^{(120)}$. Moreover, PGC1 $\alpha$ seems to be involved in mitochondrial function as it enhanced the activity of respiratory chain enzyme complexes III and IV in a cell culture model ${ }^{(121)}$. In line with these findings, AMP-activated protein kinase (AMPK), which is known to be up-regulated upon ER, was shown to affect mitochondrial development and metabolism positively $^{(122)}$.

Importantly, ER-induced unselective and selective autophagic degradation may remove old and damaged mitochondria $^{(123)}$, thereby probably reducing oxidative stress. Indeed, ER enhanced mitochondrial turnover in mouse liver, measured as reduced mitochondrial half-life ${ }^{(124)}$.

\section{Energy restriction and autophagic processes}

Autophagy is an intracellular, lysosomal degradation process that aims at recycling cell organelles, proteins and macromolecules. In all types of autophagy (macroautophagy, microautophagy and chaperone-mediated autophagy) the freight is sequestered and transported to lysosomes, where it is degraded by different hydrolases ${ }^{(125)}$. While in macro- and microautophagy heterogeneous cytoplasmic content is taken up into vesicles, chaperone-mediated autophagy is able to target, transport and degrade specific proteins ${ }^{(123,125,126)}$. However, macroautophagy may also selectively incorporate cargo (such as mitochondria) into autophagosomes, which later fuse with lysosomes to form autolysosomes $^{(127)}$. In the (auto)lysosomes, acidic hydrolases shed organelles and molecules into their components. After transport back to the cytoplasm, these components can be reused for biosynthetic or energy-generating processes ${ }^{(128)}$. Fig. 2 shows the major events of macroautophagy.

For the best-studied type of autophagy, macroautophagy (in the following referred to as autophagy), it was shown that autophagy-related proteins (ATG) initiate and perform this lysosomal degradation pathway ${ }^{(125)}$. These ATG are mostly activated under catabolic conditions. Many of them have been 


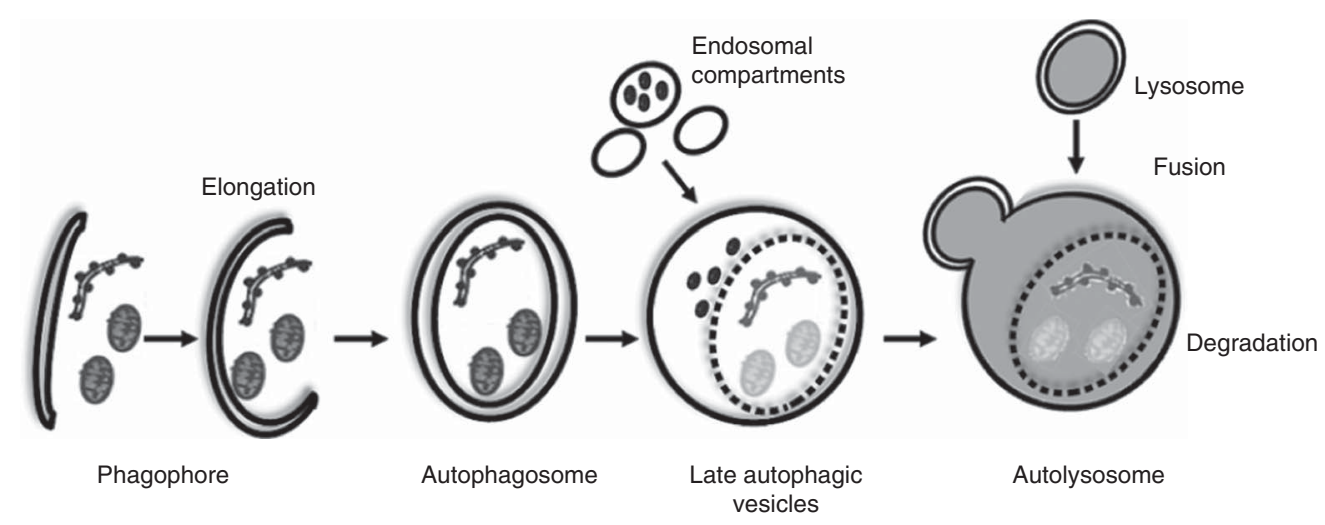

Fig. 2. Schematic overview of macroautophagy. A phagophore elongates, wraps around cytosolic components and closes to become an autophagosome. This structure fuses with endosomal vesicles to build late autophagic vesicles and finally fuses with a lysosome, thereby forming an autolysosome in which its inner membrane and its contents are degraded (adapted from Cantó \& Auwerx ${ }^{(122)}$ ).

shown to be activated by sirtuins (SIRT) and/or inhibited by mammalian target of rapamycin (mTOR) complex 1 (mTORC1), which are induced or repressed by ER, respectively ${ }^{(129-131)}$. Consistently, ATG $^{(10)}$ such as the mammalian ATG8 homologue LC3 ${ }^{(77)}$ were induced upon ER treatment.

The reason why autophagy is induced upon $\mathrm{ER}^{(8,77,132-134)}$ is most probably because ER causes a shift from development and reproduction towards maintenance. Under these circumstances autophagy is necessary for recycling of cellular material required for rebuilding essential cell structures and for generating energy ${ }^{(8,133,134)}$. Interestingly, in lifespan experiments the pro-longevity effect of ER depended on autophagy induction $^{(132)}$. In line with the finding that autophagy induction contributed to the pro-longevity effect of ER, autophagy was shown to decrease during the ageing process ${ }^{(135)}$.

By accelerating the turnover of proteins, membranes and other organelles, autophagy also contributes to maintaining efficiency of peroxisomes, ER and importantly mitochondria ${ }^{(132)}$. Thus, active autophagy could possibly counteract the age-related increase in ROS generation/oxidative stress. This potentially reduces the risk for neurodegenerative diseases like Alzheimer's, Huntington's or Parkinson's in which the accumulation of redundant proteins, followed by functional impairments and the death of post-mitotic neurons are observed. As autophagy removes aggregation-prone redundant or damaged molecules ${ }^{(136)}$ and apoptotic bodies ${ }^{(134)}$, increased autophagy might attenuate the progress of neurodegenerative diseases. Indeed, autophagy was found to be dysregulated in patients suffering from Alzheimer's disease $\mathrm{e}^{(137,138)}$, Parkinson's disease ${ }^{(139)}$ and Huntington's disease ${ }^{(140)}$. Therefore, targeting autophagy induction, for example, by ER, seems to be a valuable strategy for delaying the onset of these diseases and increasing healthspan and lifespan.

\section{Molecular targets of energy restriction \\ AMP-activated protein kinase}

In the case of limited energy supply, ATP levels decline and the AMP:ATP ratio increases which in turn activates, i.e. phosphorylates, the nutrient sensor $\mathrm{AMPK}^{(141)}$. Thus, high levels of phosphorylated AMPK (p-AMPK) are indicative of low energy supply ${ }^{(142,143)}$. Additionally, AMPK appears to be regulated by hormones like leptin and adiponectin, ghrelin and thyroxine ${ }^{(144)}$.

AMPK phosphorylation leads to activation of various downstream targets such as SIRT1, PGC1 $\alpha$ and some forkhead box $\mathrm{O}(\mathrm{FOXO})^{(145-147)}$. This in turn leads to deacetylation of transcription factors and other proteins, biogenesis of mitochondria and stress defence mechanisms. Additionally, AMPK was shown to inhibit the central kinase mTOR, which in its activated complex mTORC1 promotes cell growth and proliferation ${ }^{(141)}$.

Indeed, AMPK activation has been found to promote longevity in model organisms. Whereas decreased AMPK activity reduced the lifespan of $D$. melanogaster ${ }^{(148)}$, an increase in lifespan could be observed in yeast and C. elegans with activated $\mathrm{AMPK}^{(145,148,149)}$.

However, the results concerning the effect of ER on AMPK activity are inconsistent. While some studies found increased p-AMPK in the heart, muscle and liver of lifelong ER-fed mice $^{(150-152)}$, others did not observe any changes in $\mathrm{p}$-AMPK levels ${ }^{(153)}$.

Interesting insights come from studies that supplemented model organisms with substances that mimic ER. It could be shown that AMPK is necessary for the life-prolonging effect of such ER mimetics ${ }^{(154)}$. Additionally, the deacetylase SIRT1 was also shown to be necessary for ER-mimetic-induced lifespan extension $^{(155)}$.

\section{Sirtuins}

Various studies have shown that SIRT1 is induced by ER ${ }^{(156-158)}$. SIRT1 is part of the sirtuin family - a group of energy-sensing protein deacetylases ${ }^{(159)}$. In an energy-dependent manner ${ }^{(160)}$, SIRT1 regulates the activity of many proteins, for example, transcription factors, by changing their state of acetylation ${ }^{(161)}$. Using $\mathrm{NAD}^{+}$as a cofactor (the concentration of which rises upon limited nutrient supply), SIRT1 catalyses the transfer of a lysine-bound acetyl group from a protein substrate to $\mathrm{NAD}^{+}$, thereby forming nicotinamide, O-acetyl-ADP-ribose and the deacetylated substrate ${ }^{(162)}$. 
Via deacetylation of histones, SIRT1 might modulate the expression of several genes ${ }^{(163)}$ involved in energy metabolism. Due to their lysine and arginine residues, histones are charged positively and they form tight complexes with the negatively charged DNA, thereby impeding the RNA polymerase access to the DNA. The acetylation of lysine and arginine residues in the histone weakens its interaction with the DNA ${ }^{(163,164)}$, which renders the DNA sequences more susceptible for binding of the polymerase, leading to enhanced gene transcription. Thus, deacetylating histones might down-regulate gene expression ${ }^{(164)}$.

Additional substrates of SIRT1 include proteins that are involved in mitochondrial biogenesis and turnover. By deacetylating PGC1 $\alpha$ and thereby enhancing its activity ${ }^{(165)}$, SIRT1 might induce mitochondrial biogenesis ${ }^{(166)}$. Moreover, SIRT1 seems to enhance the activity of ATG5, 7 and $8^{(143)}$, which promotes autophagy induction ${ }^{(143,160,167)}$.

Similar to ER, increased expression of SIRT1 (or its homologues) in yeast, C. elegans, D. melanogaster and mice enhanced lifespan ${ }^{(168-171)}$. Mice overexpressing SIRT1 revealed an improved glucose homeostasis, including increased insulin sensitivity and were protected from developing $\mathrm{T}_{2} \mathrm{DM}^{(172)}$. High-fat diet-fed mice with increased SIRT1 expression seemed to be resistant to the metabolic syndrome ${ }^{(173)}$. Moreover, SIRT1 was shown to prevent metabolic syndrome-induced tumour development ${ }^{(174)}$. Via interacting with and inhibiting the binding sites of PPAR $\gamma$ (a transcription factor that regulates lipid metabolism), SIRT1 reduces the expression of its target genes in white adipocytes ${ }^{(175,176)}$. Thus, SIRT1 may also inhibit lipid storage and enhance fat mobilisation in white adipose tissue upon $\mathrm{ER}^{(176)}$

Conversely, some studies found that ER increased lifespan even in the absence of SIRT1 and other SIRT ${ }^{(177,178)}$. It could be possible that the signalling proteins of the interdependent network SIRT1, AMPK and PGC1 $\alpha$ can in part compensate for each other $^{(147)}$

\section{PPAR $\gamma$ coactivator $1 \alpha$}

The key target of Sirt1 and AMPK, the co-activator of the transcription factor PPAR $\gamma$ PGC1 $\alpha^{(146,179)}$, is also central for mediating the ER-induced lifespan-enhancing effect ${ }^{(180)}$. When activated, PGC1 $\alpha$ might even prevent age-related undesirable changes ${ }^{(181,182)}$ in skeletal and heart muscle and in adipose tissue. Apart from its role in mitochondrial biogenesis and function $^{(166)}$ in all cell types, in skeletal muscle PGC1 $\alpha$ is thought to affect the type of muscle fibre ${ }^{(183)}$. Furthermore, PGC1 $\alpha$ stimulates adaptive thermogenesis in brown adipose tissue $^{(184)}$. PGC1 $\alpha$ activity appears to prevent loss of mitochondrial function in muscles, protects from distributional and functional changes of adipose tissue and affects the energy metabolism by favouring lipids instead of carbohydrates as a main energy source ${ }^{(182)}$

While some ER studies found that nuclear PGC1 $\alpha$ levels (and subsequent increase in mitochondrial biogenesis) increased under limited nutrient supply ${ }^{(181,185)}$, others did not observe any differences in nuclear PGC1 $\alpha$ protein concentrations in rodent tissues such as heart, liver, white adipose tissue and brain ${ }^{(186)}$. However, in mice the SIRT1-mediated activation of PGC1 $\alpha$ also led to increased gluconeogenesis, enhanced glucose mobilisation and reduced levels of glycolysis ${ }^{(165)}$.

\section{Forkhead box $\mathrm{O}$}

FOXO transcription factors were also shown to be activated by SIRT1 ${ }^{(165)}$. FOXO are involved in stress defence and energy metabolism ${ }^{(187,188)}$ and induce the transcription of genes that promote autophagy and cell death ${ }^{(189,190)}$.

Apart from deacetylation, which activates FOXO, they can be regulated negatively by phosphorylation ${ }^{(191)}$. After being phosphorylated, FOXO are shuttled from the nucleus into the cytoplasm, which reduces the expression of FOXO target genes $^{(192)}$.

\section{Insulin-like growth factor 1}

The IGF-1 signalling pathway is also negatively affected under $\mathrm{ER}^{(32,193)}$. The reduced IGF-1 signalling observed under $\mathrm{ER}^{(194)}$ is usually accompanied by lowered growth hormone $(\mathrm{GH})$ concentrations $^{(32)}$, since GH promotes IGF expression ${ }^{(62)}$. An ER-induced reduction in plasma levels of free IGF-1 was shown to be pro-apoptotic and anti-proliferative ${ }^{(195)}$ and is therefore potentially chemopreventive.

Indeed, $\mathrm{GH}^{(196)}$ and IGF-1 receptor ${ }^{(197,198)}$ deficiencies were shown to increase lifespan, whereas GH overexpression led to premature ageing and shortened lifespan in mice ${ }^{(196)}$. Dwarf mice that display reduced IGF-1/GH signalling lived considerably longer compared with normal-sized wild-type mice, mainly because they had a reduced incidence of neoplasms ${ }^{(199)}$. Furthermore, it was shown that low IGF-1 levels were related to survival in long-lived humans ${ }^{(200)}$.

Additionally to decreased levels of growth factors and hormones, the reduction of insulin secretion upon ER feeding could also account for its chemopreventive effect. Hyperinsulinaemia is strongly related to high levels of oxidative stress $^{(201)}$ and reduced rates of autophagy ${ }^{(202)}$, leading to increased generation of damaged macromolecules and decreased degradation of damaged proteins.

Another consequence of increased IGF-1 signalling is the induction of phosphoinositide-dependent protein kinase, which in turn activates protein kinase B by phosphorylation ${ }^{(203)}$, thereby activating mTOR.

\section{Mammalian target of rapamycin}

mTOR is a seronine/threonine protein kinase that is involved in several regulatory processes. It is suggested that it influences cell growth, including proliferation, transcription and protein synthesis, as well as cell survival ${ }^{(204)}$.

Due to its central role in proliferation and cellular growth processes, mTOR has long been studied as a molecular target for cancer therapy ${ }^{(205)}$. Inhibiting mTOR activity genetically or pharmacologically increased lifespan in yeast ${ }^{(206,207)}$, C. elegans ${ }^{(208,209)}$ and D. melanogaster ${ }^{(210)}$.

Consistent with decreased IGF-1 and GH signalling ${ }^{(199)}$, which are upstream regulators of mTOR, mTOR signalling is also reduced in dwarf ${ }^{(211)}$ and ER-fed mice ${ }^{(212)}$. Inhibition of mTOR 
leads to autophagy induction ${ }^{(213,214)}$ possibly via dephosphorylation of ATG13 and the mammalian Atg1 homologues Unc-51 like autophagy activating kinases 1 and 2, which are essential for mTOR-dependent autophagy ${ }^{(130,131)}$.

\section{Limitations and adverse effects of energy restriction}

Evaluating ER as a potential pro-longevity treatment, it is necessary to keep in mind some of its adverse effects (see Table 1). First of all, it seems almost infeasible to follow a lifelong ER regimen that requires a reduction of energy intake of up to $40 \%{ }^{(215)}$ without being malnourished at any time. Another critical issue in ER experiments might be decreased bone mineral density as observed in primates and rodents ${ }^{(32)}$ as well as in a long-term ER study in human subjects ${ }^{(216)}$. Deficiencies in skin wound healing - seen in restrictively fed rats ${ }^{(217)}$ - and decline in concentrations of gonadal steroids ${ }^{(54)}$ could impair health-related quality of life. Furthermore, symptoms such as starving, cold and reduced libido persist during long-term ER and the social aspect of eating food should not be neglected ${ }^{(36)}$. Importantly, ER-fed old mice seem to be more susceptible to infections $^{(218)}$, which could even decrease lifespan.

An alternative to ER is the 'alternate day fasting' regimen. In this modified ER concept, dietary intake is partially or completely limited every other day, whereas food consumption remains unrestricted on the remaining days ${ }^{(219)}$. Although it could be expected that a higher food intake in ad libitum phases compensates or even overcompensates for energy shortage during the restriction days, several health-promoting effects were seen in alternate day fasting compared with control groups with unlimited food access ${ }^{(220-223)}$. However, this nutritional concept also seems hard to follow in modern society and possible side effects need to be studied in more detail.

\section{Energy restriction mimetics}

Because of its limitations, alternatives to ER that could prevent or retard the onset of ageing-related pathologies to a similar extent as ER are being sought. Since it takes very long to generate data on the influence of dietary regimens, supplements or pharmacological substances on human lifespan and age-related diseases there is only limited information on general ageing patterns in specific organs and tissues. Using broad-range microarrays, gene expression profiles associated with the ageing process have been identified. By comparing these patterns of aged individuals to subjects undergoing ER and those supplemented with potential ERM, the anti-ageing potential of candidate substances can easily be assessed ${ }^{(92)}$. Results of ongoing studies identifying potential ERM are published regularly by the NIA Interventions Testing Program. A comprehensive review on ER effects with a focus on epigenetic changes was recently published by Chung et al. ${ }^{(224)}$. Moreover, Ingram et $a l .{ }^{(225)}$ have established criteria that should be met before a substance is considered an ERM. First, candidate substances should not significantly influence long-term dietary intake in order to prevent positive results merely because of reducing energy consumption. Second, the candidate substance should induce metabolic, hormonal and physiological changes that are comparable with the effects of ER. And third, it should induce an ER-like stress response. It is hypothesised that through meeting these three criteria, dietary supplementation with the candidate substance may have a positive influence on healthspan and lifespan ${ }^{(226)}$. According to Selman, the elongation of healthspan by putative ERM candidates should be more emphasised $^{(227)}$.

The criterion proposed by Lane et al. ${ }^{(228)}$ resembles these points. They state that without altering food intake the potential ERM should target energy metabolism since this seems to be the underlying mechanism of the beneficial ER effects.

\section{Putative energy restriction mimetic candidate substances}

ERM target various molecules and processes that have been described in the 'Cellular processes affected by energy restriction' section. A putative ERM that targets glucoregulation and inhibits glycolysis is the glucose analogue 2-deoxy-D-glucose $(2 \mathrm{DG})^{(36)}$. Recently, glucosamine has been discussed as mimicking a low-carbohydrate diet and thus potentially acting as an $\operatorname{ERM}^{(229)}$.

Further ERM candidates are the biguanides that have been used in the treatment of T2DM since they lower insulin/IGF-1 signalling and activate $\mathrm{AMPK}^{(36)}$. While formerly phenformin and butformin were used alongside metformin, nowadays only metformin is approved for T2DM treatment. Thus, despite studies showing a prolonged lifespan in phenformin- and butformin-supplemented rats ${ }^{(230,231)}$, metformin currently is the best studied biguanide in terms of mimicking ER. Oxaloacetate seems to activate AMPK-related pathways, thereby increasing lifespan in a nematode model. However, supplementation trials in mice did not reveal any pro-longevity effect of oxaloacetate ${ }^{(232)}$

Table 1. 'Side effects' of energy restriction

\begin{tabular}{llc}
\hline Negative effect seen upon energy restriction & Model organism in which side effect was seen & References \\
\hline Immunosuppression (increased sensitivity to viral/bacterial infections) & Mus musculus & $(218)$ \\
Loss of bone mineral density & Rodents, primates and man & $(32)$ \\
Impaired wound healing & Rattus norvegicus & $(217)$ \\
Delayed sexual maturity and reduced levels of sexual hormones & Macaca mulatta & $(34,54)$ \\
& Mus musculus & $(33)$ \\
Decreased body temperature & R. norvegicus & $(36)$ \\
Social exclusion and missing feasibility of energy restriction & Man & \\
\hline
\end{tabular}


Another substance class suggested as possessing prolongevity effects are anti-lipolytic compounds such as the nicotinic acid derivative acipimox ${ }^{(233)}$ or 3,5- dimethylpyrazole ${ }^{(234)}$. Additionally to their lowering effect on plasma lipids, they are thought to be glucose- and insulin-decreasing as well as autophagy-inducing agents. These observations all point to potential ER-like effects. Unfortunately, studies looking at lifespan upon/after treatment with anti-lipolytic drugs are rare ${ }^{(36)}$. Further ERM candidates can be found among SIRT stimulators, particularly stilbenes. Systemic SIRT1 activators are known for their metabolism-stimulating and body fat-reducing effects ${ }^{(235)}$. The best-studied member of this group is resveratrol (RSV), which has been shown to increase lifespan in some species. Nicotinamide might also be considered a putative ERM since it was shown to activate SIRT. Interestingly, nicotinamide and RSV induce autophagy which might contribute to their ER-mimicking potential ${ }^{(236)}$. Autophagy-inducing agents might also promote ER-like phenotypes independently of SIRT regulation. Spermidine (SPD) was shown to induce autophagy and thereby increase lifespan in some species without affecting SIRT $^{(133)}$. Another target molecule for ERM is the proliferation and cell growth-promoting kinase mTOR. Indeed, supplementation experiments with the pharmacological mTOR inhibitor rapamycin produced promising results.

Furthermore, agents that affect mitochondrial biogenesis or the circadian rhythm may mediate ER-mimicking effects. Antioxidants such as lipoic acid that reduce ROS production by improving mitochondrial performance or increasing the production of endogenous antioxidants are also interesting putative ERM. Because of its influence on the circadian rhythm, melatonin might be helpful in managing body weight and preventing chronic diseases and premature deaths ${ }^{(237)}$.

Sometimes anorectics like amphetamines are discussed as ERM candidates ${ }^{(36)}$. But due to their considerable reduction of food and consequently energy intake, anorectics cannot be considered ERM according to the criteria mentioned above $^{(226,228,230)}$.

Postulated mechanisms and potential limitations of the best-studied and most promising energy restriction mimetics

The following section will focus on postulated mechanisms and potential limitations of the best-studied and most promising ERM as found in recent literature (for a summary, see Table 2).

\section{2-Deoxy-D-g/ucose}

2DG (Fig. 3) was one of the first substances discussed as a possible $\mathrm{ERM}^{(238)}$. As a glucose analogue it differs from glucose only in that it lacks one hydroxyl group at $\mathrm{C}^{(13)}$. After intestinal absorption and entering the circulation, 2DG is taken up into cells using the same transporters as glucose. 2DG is phosphorylated immediately by a hexokinase and accumulates intracellularly since it cannot be metabolised by phosphohexose isomerase ${ }^{(40)}$. Thereby, it competitively inhibits glucose utilisation, reduces the amounts of available energy ${ }^{(239)}$ and might consequently mimic the effects of $\mathrm{ER}^{(13)}$.

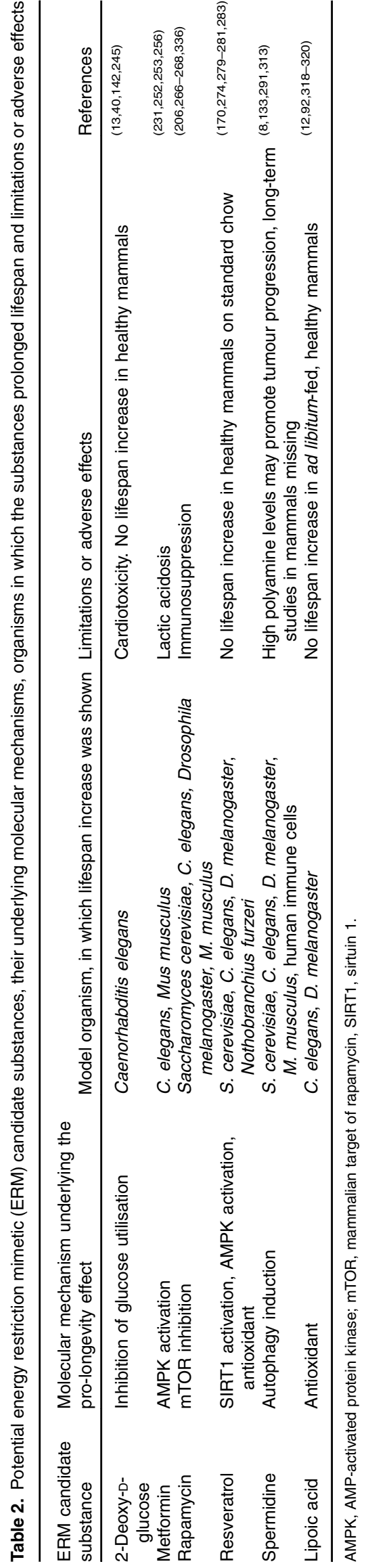




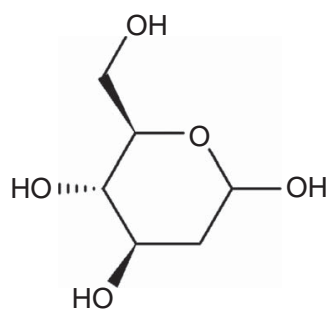

Fig. 3. Chemical structure of 2-deoxy-D-glucose.

Indeed, in rodents, adding 2DG to the diet led to ER-similar phenotypes $^{(32)}$ including decreased body weight, blood glucose $^{(240)}$, insulin ${ }^{(241)}$, body temperature ${ }^{(242)}$ and heart rate $^{(241)}$. Moreover, 2DG was shown to induce protection against oxidative stress ${ }^{(243)}$

Additionally, application of 2DG elevated protein levels of SIRT1 and p-AMPK in MCF-7 cancer cells ${ }^{(142)}$. Since the inhibition of glycolytic processes by $2 \mathrm{DG}$ is followed by a limitation of cellular energy supply, ATP levels are reduced and subsequently the AMP:ATP ratio is increased leading to AMPK activation which increases the $\mathrm{NAD}^{+}: \mathrm{NADH}$ ratio and activates SIRT1 $^{(244)}$.

In fact, Schulz et al. ${ }^{(245)}$ reported enhanced mean and maximum lifespan of $C$. elegans upon 2DG supplementation. However, these results could not be verified in mammals. Longterm studies in rodents revealed cardiotoxic effects of 2DG treatment at concentrations which were necessary for ER-like effects $^{(13)}$. In a long-term feeding trial in rats, 2DG was shown to reduce lifespan dose-dependently ${ }^{(13)}$. However, at lower concentrations which did not seem toxic, 2DG exerted healthpromoting effects in a 5-week supplementation study in tumour-prone rats where it inhibited cancer growth ${ }^{(142)}$.

In conclusion, 2DG-induced ER-like phenotypes in laboratory animals are possibly outweighed by its cardiomyopathic effects observed in some studies. Toxicity thresholds should therefore be considered when planning long-term or even lifelong 2DG supplementation studies. Thus, further studies on dose-dependent efficiency and toxicity are needed.

\section{Metformin}

The biguanide metformin (Fig. 4) has been used for treating diabetes for a long time ${ }^{(246)}$. Due to its potential of inducing ERlike effects, metformin has been considered an ERM candidate substance ${ }^{(231)}$. Metformin was shown to suppress gluconeogenesis and promote insulin sensitivity and glycolysis in diabetic subjects ${ }^{(246,247)}$. Moreover, intestinal glucose absorption and plasma glucose and lipid concentrations were decreased $^{(248)}$

In different tumour-prone rodent models and in diabetic patients incidence and progression of cancer were decreased by metformin ${ }^{(36,231,249,250)}$. Additionally, risk factors for the development of CVD were reduced upon metformin treatment ${ }^{(251)}$. Most probably, the delay in the onset of chronic diseases such as cancer and hypertension is the main reason for the longevity-promoting effect seen in $C$. elegans and $\operatorname{mice}^{(231,252)}$.<smiles>CN(C)C(=N)NC(=N)N</smiles>

Fig. 4. Chemical structure of metformin.

Interestingly, metformin caused a reduction in body weight in several studies without significantly decreasing energy intake $\mathrm{e}^{(6,231)}$. Since a reduction in body weight is associated with an increased AMPK activation, it seems reasonable to assume a contribution of AMPK to the beneficial effects of metformin. Indeed, the levels of p-AMPK were found to be elevated upon metformin supplementation ${ }^{(6,253)}$. Potential longevitypromoting effects of AMPK and its downstream targets have been described earlier in this article.

Metformin probably addresses further targets that also contribute to the observed increase in lifespan ${ }^{(248)}$. In rodent models metformin was seen to mimic the hepatic and muscular transcriptional ER response ${ }^{(6,254,255)}$. These gene expression data indicate improved mitochondrial function, glucose and lipid metabolism, reduced apoptotic rates and inflammation, as well as enhanced stress response. In particular, mRNA expression and nuclear protein levels of the central antioxidant transcription factor Nrf2 were found to be up-regulated. Additionally, mRNA concentrations of its downstream targets SOD, NQO1 and NQO2 were elevated compared with the control animals. In contrast, expression of pro-inflammatory genes like NF- $\mathrm{kB}$ seemed decreased after metformin treatment ${ }^{(6)}$.

Despite these promising effects regarding the delay of the ageing process, some impairments of chronic metformin application have to be taken into account. Metformin is suggested as causing lactic acidosis when applied at higher doses for a longer period $^{(256)}$. Indeed, microarray analyses revealed increased mRNA concentrations of cytosolic lactate dehydrogenase (a key enzyme in lactic acid generation) in the liver and muscle of metformin-supplemented mice ${ }^{(6)}$. However, metformin was applied at doses that were higher than the doses used in human subjects and the toxicity of metformin seems to depend on the dose. Current meta-analyses and reviews on metformin-treated T2DM patients concluded that the increased incidence of lactic acidosis more probably resulted from an underlying systemic dysfunction than from the metformin treatment ${ }^{(257,258)}$. Moreover, metformin supplementation may be contraindicated in individuals suffering from renal diseases ${ }^{(259)}$ since metformin induced renal failure in rodents when applied at high concentrations. Despite metformin being a promising ERM candidate, supplementation studies in healthy mammals have not always observed a clear lifespan-enhancing effect ${ }^{(226)}$. For example, a study in healthy rats supplemented with metformin failed to show a pro-longevity effect $^{(231)}$, whereas a study in C57BL/6 mice showed longevitypromoting effects after metformin treatment ${ }^{(6)}$.

\section{Rapamycin}

Rapamycin (Fig. 5), a complex macrolide antibiotic, has been used because of its immunosuppressive effects ${ }^{(260)}$ after organ 


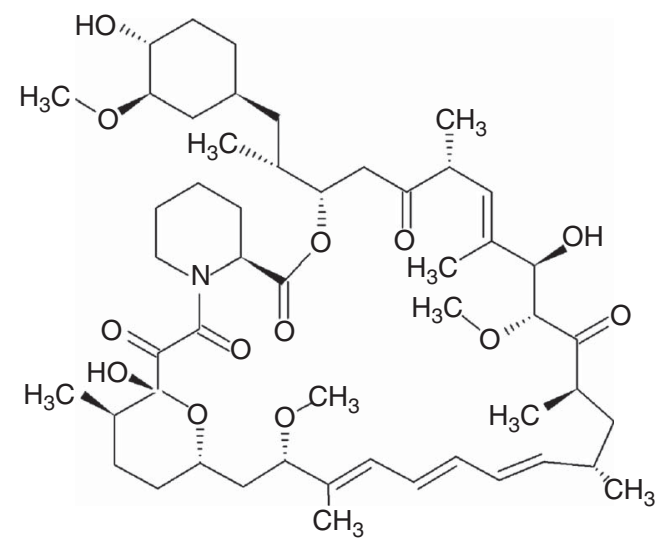

Fig. 5. Chemical structure of rapamycin.

transplantations and because of its antiproliferative properties in cancer treatment ${ }^{(261,262)}$. It has long been known that rapamycin exerts its antiproliferative effects via inhibition of mTOR signalling ${ }^{(263)}$. Possibly, reduced mTOR activation decreases cancer risk and therefore prolongs survival in rapamycintreated subjects. After discovering that deleterious TOR mutations in yeast promoted longevity, rapamycin was suggested as being an ERM in $2006^{(206)}$. Indeed, it has been shown to decelerate senescence in vitro (in non-cancerous cell lines) and to possess lifespan-enhancing properties in several model organisms such as Saccharomyces cerevisiae ${ }^{(206,264)}$, C. elegans, D. melanogaster ${ }^{(265,266)}$ and mice ${ }^{(266-268)}$.

How rapamycin interferes with mTOR is still under discussion. It has been hypothesised that rapamycin could bind to the heterodimer of the FK506 binding protein (FKBP)-type peptidyl-prolyl cis-trans-isomerase and the FKBP-rapamycinassociated protein. As such a heterotrimer, rapamycin might form complexes with mTOR, thereby inhibiting the formation of the complex mTORC1 and consequently cell proliferation and cell growth ${ }^{(269)}$. Of interest, via inhibition of mTORC1, rapamycin was also shown to activate autophagy by up-regulating ATG $1^{(266,270,271)}$. Similar to findings from ER studies, prolonged lifespan induced by low doses of rapamycin was shown to depend on autophagy since rapamycin failed to enhance survival in atg1- and atg7-deficient yeast ${ }^{(264)}$. Several beneficial outcomes of rapamycin administration, which may contribute to its pro-longevity effect, were observed in clinical and pre-clinical studies; namely, rapamycin seemed to alleviate the ageing-related diseases T2DM, the metabolic syndrome, atherosclerosis, neurodegeneration and some kinds of cancer ${ }^{(272,273)}$. However, body weight does not appear to be affected by rapamycin administration in mice fed standard diets ${ }^{(267)}$.

A limitation for rapamycin use as an ERM in humans results from its immunosuppressive action. While mice housed in specific pathogen-free cages are unlikely to acquire infections despite being supplemented with immunosuppressants, humans may not benefit from rapamycin due to severe bacterial or viral diseases $^{(226)}$. Moreover, animals treated with high rapamycin doses suffered from disturbed lipid or glucose homeostasis, skin irritations, anaemia or impaired wound healing ${ }^{(248)}$. Currently, studies are being carried out by the NIA to evaluate the most effective dose for promoting longevity in rodents ${ }^{(268)}$.<smiles>Oc1ccc(/C=C/c2cc(O)cc(O)c2)cc1</smiles>

Fig. 6. Chemical structure of resveratrol.

\section{Resveratrol}

RSV (Fig. 6), a naturally occurring stilbene with antioxidant capacity $^{(274)}$, is mainly found in the skin of red grapes and therefore in red wine ${ }^{(275,276)}$. Considerable amounts can also be detected in the roots of the medical plant Japanese knotweed $^{(277)}$ and lower amounts in other fruits ${ }^{(278)}$. In a NIA in vitro screening programme, RSV was identified as a SIRT1 activator in 2003. As SIRT1 seems to be a crucial player in ERmediated lifespan extension, RSV was additionally tested for its lifespan-enhancing effects in S. cerevisiae. Due to the promising results of this trial ${ }^{(279)}$ several studies have been conducted to verify the lifespan-enhancing properties of RSV. Indeed, RSV has shown survival enhancing effects in yeast, C. elegans, some D. melanogaster experiments ${ }^{(170)}$, Nothobranchius furzeri ${ }^{(280)}$ and high-fat diet-fed mice ${ }^{(281)}$. Additionally, Morselli et al. proposed that RSV-mediated SIRT1 activation was followed by the induction of autophagy, which appears to be important for the lifespan-enhancing effect of $\mathrm{ER}^{(8)}$.

However, in other fly studies ${ }^{(278,282)}$ and in mice fed a standard chow RSV did not prolong lifespan ${ }^{(268,283,284)}$. Nevertheless, in standard chow-fed mice supplemented with RSV several tissues revealed ER-like gene expression patterns, and anti-inflammatory, cardio- and osteoprotective effects as well as improved locomotor activity were observed ${ }^{(283)}$.

While it seems that SIRT1 might be responsible for the beneficial effects of $\mathrm{RSV}^{(281)}$ the exact mechanism of SIRT1 remains unclear. RSV may be binding to the regulatory ${ }^{(285)} \mathrm{N}$-terminal subunit of SIRT1. Subsequently, a conformational change could take place, which in turn could lead to an enhanced SIRT1 deacetylation activity ${ }^{(279)}$. Thus, the red wine polyphenol would seem to be an allosteric SIRT1 activator ${ }^{(8,279)}$.

Intriguingly, there are reports that the observed increase in SIRT1 deacetylase activity due to RSV could have been a result of a methodological error ${ }^{(286,287)}$. If the enzyme activity measurement is not performed with fluorochrome-conjugated substrates (as it usually is) but with natural substrates, RSV does not increase SIRT1 activity ${ }^{(286)}$.

However, Park et al. showed that RSV inhibits cAMPdegrading phosphodiesterases, which in turn leads to an activation of the AMPK pathway. They further argue that this increases $\mathrm{NAD}^{+}$levels and that SIRT1 activation is a consequence of a RSV-mediated rise in $\mathrm{NAD}^{+}$levels ${ }^{(288)}$. These findings could explain why Pacholec et al. could not detect SIRT1 activation when measuring the enzyme activity in vitro ${ }^{(286)}$.

Interestingly, experiments in knockout animals have shown that apart from SIRT ${ }^{(170)}$ AMPK is also necessary for the pro-longevity effect of $\mathrm{RSV}^{(154)}$. The beneficial effects of RSV on insulin 
sensitivity, motor function, mitochondrial performance $e^{(159,281)}$ as well as decreased body weight ${ }^{(154,159)}$ were not seen in AMPKdeficient animals ${ }^{(154)}$. A recent publication has described a mechanism for AMPK activation by RSV in vitro that does not depend on SIRT1 but on the tyrosyl transfer-RNA synthetase. RSV may fit into the active site of the tyrosyl transfer-RNA synthetase, thereby leading to nuclear translocation of this enzyme and consequently activation of the poly(ADP-ribose) polymerase 1 which in turn could activate downstream targets such as AMPK, FOXO and SIRT. Intriguingly, this happened at up to 100-fold lower doses than in previous studies ${ }^{(289)}$.

In contrast to many other ERM candidate substances, hardly any adverse effects have been reported for RSV so far. Only a study applying very high RSV doses observed cases of premature death ${ }^{(290)}$. However, it needs to be kept in mind that the efficiency of RSV in reducing mortality rates in healthy mammals and the appropriate dose of RSV for supplementation are still under discussion.

\section{Spermidine}

Spermidine (SPD; Fig. 7) is a naturally occurring polyamine that is essential for various cellular processes. Along with other endogenous polyamines such as spermine and putrescin it was shown to modulate various cellular processes such as proliferation, differentiation and cell death ${ }^{(291)}$.

Looking at particular polyamines, putrescine and cadaverine turn out to be rather negatively annotated molecules since they are enhanced in tissues in chronic diseases such as cancer ${ }^{(292)}$, Parkinson's ${ }^{(293)}$ and pancreatitis ${ }^{(294)}$. In contrast, SPD seems to be protective against age-related pathological changes ${ }^{(133)}$. Spermine and SPD have already been described as exerting anti-inflammatory effects ${ }^{(295,296)}$. Additionally, their levels were shown to be reduced in Alzheimer's disease ${ }^{(297)}$. Thus, the restoration of SPD and spermine levels might ameliorate Alzheimer's pathology. Moreover, due to its anti-inflammatory properties, SPD has been suggested for the treatment of multiple sclerosis ${ }^{(298)}$ and sepsis ${ }^{(299)}$.

As the endogenous synthesis of SPD declines with age ${ }^{(300,301)}$, supplementation with SPD could increase the plasma concentrations at a higher age ${ }^{(291)}$. Food rich in SPD includes soya and other beans, green tea and mushrooms ${ }^{(302,303)}$. SPD rich diets are consumed traditionally in Asian $^{(304)}$ and Mediterranean ${ }^{(305)}$ regions.

Recently, elevated SPD relative to total polyamine concentrations have been observed in the plasma of centenarians compared with younger counterparts ${ }^{(306)}$. Consistently, SPD supplementation in aged mice ${ }^{(291)}$, S. cerevisiae, C. elegans, D. melanogaster and human immune cells ${ }^{(133)}$ increased lifespan.

Some researchers assume SPD to exert its longevitypromoting effects via induction of autophagy ${ }^{(8,133)}$. Autophagy is known to be reduced at a higher age ${ }^{(134,307)}$, and seems to counteract senescence when induced ${ }^{(307,308)}$.

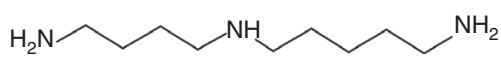

Fig. 7. Chemical structure of spermidine.
In vitro experiments revealed that SPD treatment inhibited the activity of histone acetyltransferases in yeast and mouse liver extracts ${ }^{(8,133)}$. Gene expression depends on the acetylation state of histones. The negatively charged chromatin can be wrapped around the histones more tightly when more of the lysine and arginine residues in the histone molecules remain deacetylated, i.e. positively charged. Thus, histone acetylation and deacetylation may alter the accessibility of certain DNA sections to transcriptionally active enzymes ${ }^{(309)}$. Therefore, a high number of deacetylated histones - as observed after SPD treatment ${ }^{(133)}$ - leads to modified expression of several genes $^{(309)}$. Recently it has been reported that SPD-treated yeast expressed Atg7, 11 and 15, which are involved in autophagy induction, at enhanced levels ${ }^{(8)}$. Indeed, SPD failed to increase lifespan in atg-deficient yeast ${ }^{(133)}$.

However, in D. melanogaster, recent data suggest a contribution of non-autophagic mechanisms to the improved response to oxidative stress upon SPD supplementation although these additional underlying signalling pathways have not been fully elucidated ${ }^{(310,311)}$.

SPD is still a very young topic in longevity research; therefore studies on potential negative side effects are rare. However, elevated concentrations of polyamines are thought to be related to an increased incidence of cancer. Possibly, oxidative damage, caused by oxidation of polyamines in general, contributes to this effect ${ }^{(303)}$.

Potential limitations in the use of SPD as an ERM result from observations that increased polyamine concentrations caused enhanced tumour progression ${ }^{(312-314)}$. In fact, putative anticancer agents inhibit polyamine metabolism ${ }^{(303)}$. However, in these studies polyamines were applied to model organisms with existing tumours or cells that had undergone oncogenic transformation $^{(291)}$. Up to now, there is no direct evidence for cancer-promoting effects of enhanced SPD intake in healthy animals. So far, however, there are no long-term studies in healthy mammals.

\section{Lipoic acid}

The disulfide derivative of octanoic acid is well known for its antioxidant activity that is also exerted by its reduced form dihydrolipoic acid ${ }^{(315)}$. Apart from its antioxidant effect, lipoic acid (Fig. 8) is an essential cofactor for certain enzyme complexes, for example, pyruvate dehydrogenase and $\alpha$-ketoglutarate dehydrogenase ${ }^{(316)}$.

Due to the beneficial effects of antioxidants in general, it seems worth examining the healthspan- and lifespan-extending properties of lipoic acid.

Lipoic acid exists as two stereoisomers, $R$ - $\alpha$-lipoic acid and $S$ - $\alpha$-lipoic acid. The biologically more active stereoisomer<smiles>O=C(O)CCCC[C@@H]1CCSS1</smiles>

Fig. 8. Chemical structure of $R$-a-lipoic acid. 
$R$ - $\alpha$-lipoic acid can be synthesised endogenously from fatty acids (octanoic acid) and a sulfur source (cysteine) or taken up with food ${ }^{(317)}$. Exogenously supplied lipoic acid is mostly bound to lysine. As lipoyllysin it can be found in vegetables, for example, spinach, broccoli and tomatoes, as well as in animal tissues like liver, heart and kidney ${ }^{(12)}$.

According to some popular ageing theories, free radicals are probably a major reason for the development of ageingassociated diseases ${ }^{(10,248)}$ Thus, enhancing the supply of exogenous antioxidants might counteract the process of ageing and increase lifespan similar to ER. However, even though lipoic acid is a potent antioxidant, there are only a few studies showing increased lifespan in lipoic acid-supplemented invertebrates (C. elegans, D. melanogaster $)^{(318-320)}$. While experiments in rodents did not find longevity-promoting effects under physiological conditions (in healthy animals with unrestricted food supply) $)^{(12,92,321)}$ immunosuppressed mice receiving a lipoic acid-supplemented diet revealed longer lifespans than controls ${ }^{(322)}$. Another experiment showed that mice that were re-fed ad libitum after being on ER lived longer when the ad libitum feed was supplemented with lipoic acid compared with non-supplemented ad libitum feed-receiving mice $^{(12)}$.

Although evidence for lifespan-enhancing properties in rodents is missing, there are several publications pointing to the notion that lipoic acid counteracts age-related disorders. Lipoic acid was shown to reduce oxidative stress and damage in the heart muscle and brain in rats, thereby potentially ameliorating cardiac and neurodegenerative diseases ${ }^{(92,323-326)}$.

Apart from directly scavenging ROS and recycling of other antioxidants like vitamin $\mathrm{C}$ or glutathione ${ }^{(315)}$, lipoic acid might also decrease oxidative damage to macromolecules by decreasing the amount of ROS that is produced within the mitochondrial electron chain ${ }^{(327)}$. This protective effect may be mediated by enhancing the expression of UCP, which use the electrochemical gradient at the inner mitochondrial membrane to generate heat instead of $\mathrm{ATP}^{(328)}$. Fatty acids are potent inductors of mitochondrial $\mathrm{UCP}^{(329,330)}$. It is assumed that lipoic acid might induce uncoupling due to its structural similarity to fatty acids ${ }^{(327)}$.

The controversial outcome of studies on lipoic acid regarding lifespan could be in part explained by the low stability of lipoic acid. Encapsulating lipoic acid in a cyclodextrin cavity increased its solubility $^{(331)}$ and stability ${ }^{(331,332)}$. Interestingly only this complexed form of lipoic acid increased energy expenditure in old mice. Most probably this was mediated by the induction of $\mathrm{UCP}^{(333)}$. Importantly, a positive correlation between the metabolic rate, mitochondrial uncoupling and the lifespan of mice was reported $^{(334)}$. However, clear evidence for a positive relationship between lipoic acid intake and lifespan in healthy mammals is still lacking.

For a brief summary of the suggested molecular targets of the ERM candidates reviewed in this paper, see Fig. 9.

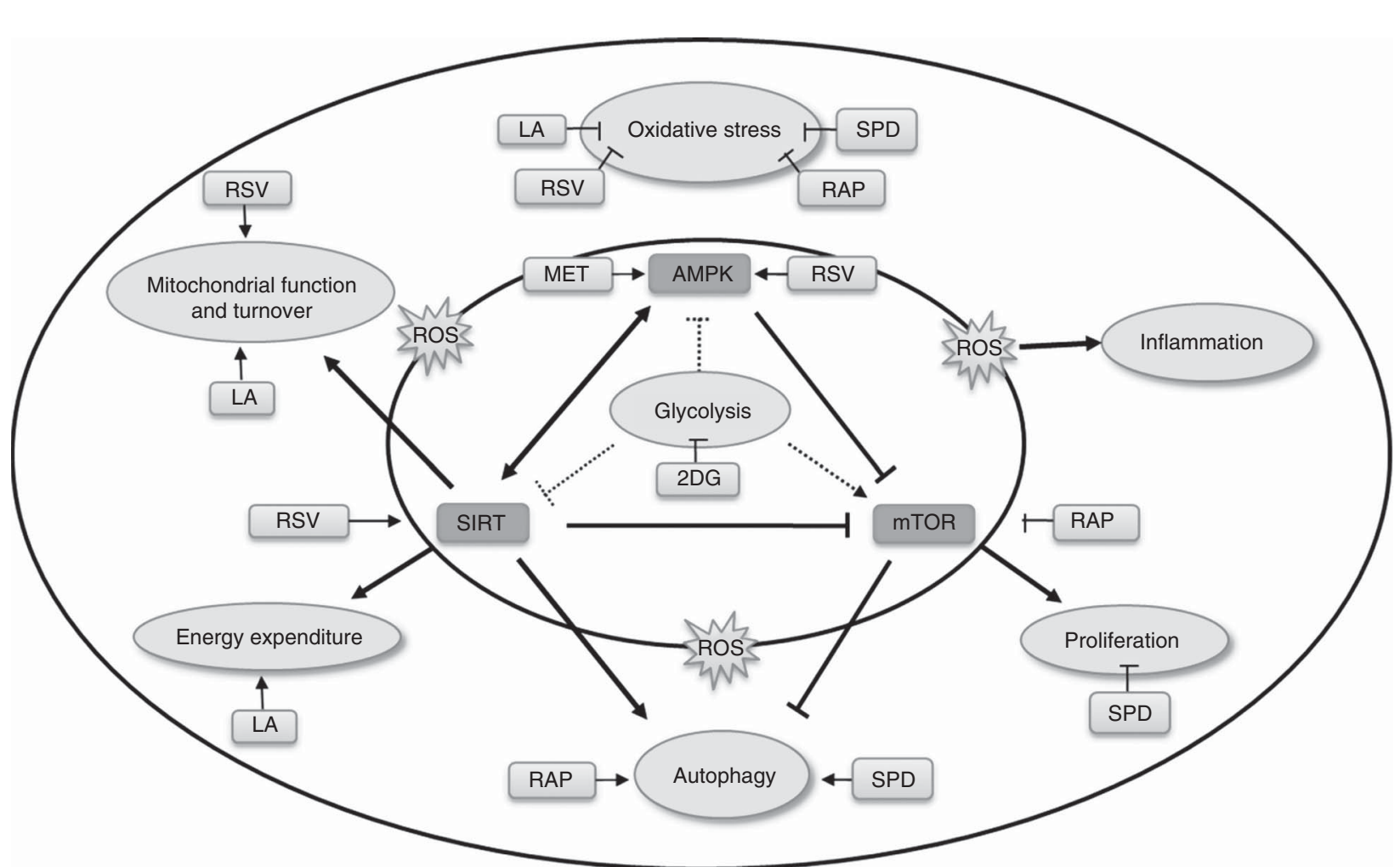

Fig. 9. Schematic overview of the suggested molecular targets of the energy restriction mimetic candidate substances 2-deoxy-D-glucose (2DG), metformin (MET), rapamycin (RAP), resveratrol (RSV), spermidine (SPD) and lipoic acid (LA). 2DG inhibits the central process of glycolysis, thereby favouring the activities of AMPactivated protein kinase (AMPK) and sirtuin (SIRT). MET increases AMPK activity, indirectly leading to increased autophagy and mitochondrial turnover. RAP inhibits mammalian target of rapamycin (mTOR) signalling, thereby favouring autophagy and inhibiting proliferative processes. In addition to its antioxidant capacity, RSV is thought to increase SIRT and AMPK activity. SPD might up-regulate the antioxidant response, enhance autophagy and decrease proliferation. LA might improve mitochondrial function, increase energy expenditure and reduce oxidative stress. ROS, reactive oxygen species. 


\section{Conclusion}

Despite various benefits of ER, such as a reduced risk for age-related chronic diseases, the limitations of ER need to be considered. In order to prevent adverse side effects like immunosuppression or loss of bone mineral density, ERM should only imitate the positive effects. However, until now no substances have been found that repeatedly mimic the positive effects seen in restrictively fed models without adverse effects for mammals. In order to possibly improve the healthpromoting effects or reduce negative side effects of single substances, ERM candidates should be tested for putative synergistic interactions. Moreover, it needs to be ascertained if other components found in Mediterranean or Asian ('MediterrAsian,(335) ${ }^{\text {(3) }}$ diets might exert ER-like effects similar to RSV and SPD. There are only a few studies that have investigated ER effects in humans, since lifespan studies in human subjects are difficult to perform (at the very least because of the length of human life). However, by means of measuring longevity biomarkers that have already been established in rodent or primate ER lifespan studies, putative healthspan- and lifespanpromoting effects in humans may be extrapolated. But due to the lack of feasibility of ER and the limitations of ERM candidate substances, alternative ER patterns should also be considered in future studies since there is strong evidence that moderate restriction regimens may improve healthspan ${ }^{(220-223)}$. Thus, more research is needed in order to find new dietary strategies that imitate positive ER effects without its downsides.

\section{Acknowledgements}

This research received no specific grant from any funding agency, commercial or not-for-profit sectors.

The authors contributed to the present review as follows: conception and design of the work (S. N., G. R., K. P. and P.H.); acquisition, analysis or interpretation of data (S. N. and K. P.); drafting of the manuscript (S. N. and K. P.); revising work critically for important intellectual content (K. P., G. R. and P.H.); and approval of the final version (S. N., K. P., P. H. and G. R.).

There are no conflicts of interest.

\section{References}

1. World Heath Organization (2005) Preventing chronic diseases: a vital investment. http://www.who.int/chp/chronic_ disease_report/full_report.pdf (accessed November 2014).

2. Berghofer A, Pischon T, Reinhold T, et al. (2008) Obesity prevalence from a European perspective: a systematic review. BMC Public Health 8, 200.

3. Stevens GA, Singh GM, Lu Y, et al. (2012) National, regional, and global trends in adult overweight and obesity prevalences. Popul Health Metr 10, 22.

4. Alberti KG, Eckel RH, Grundy SM, et al. (2009) Harmonizing the metabolic syndrome: a joint interim statement of the International Diabetes Federation Task Force on Epidemiology and Prevention; National Heart, Lung, and Blood Institute; American Heart Association; World Heart Federation; International Atherosclerosis Society; and International Association for the Study of Obesity. Circulation 120, 1640-1645.
5. Krauss RM, Deckelbaum RJ, Ernst N, et al. (1996) Dietary guidelines for healthy American adults. A statement for health professionals from the Nutrition Committee, American Heart Association. Circulation 94, 1795-1800.

6. Martin-Montalvo A, Mercken EM, Mitchell SJ, et al. (2013) Metformin improves healthspan and lifespan in mice. Nat Commun 4, 2192.

7. Ford ES, Giles WH \& Dietz WH (2002) Prevalence of the metabolic syndrome among US adults: findings from the third National Health and Nutrition Examination Survey. JAMA 287, 356-359.

8. Morselli E, Galluzzi L, Kepp O, et al. (2009) Autophagy mediates pharmacological lifespan extension by spermidine and resveratrol. Aging 1, 961-970.

9. Toth MJ \& Tchernof A (2000) Lipid metabolism in the elderly. Eur J Clin Nutr 54, Suppl. 3, S121-S125.

10. Kim HJ, Jung KJ, Yu BP, et al. (2002) Modulation of redoxsensitive transcription factors by calorie restriction during aging. Mech Ageing Dev 123, 1589-1595.

11. Rae MJ, Butler RN, Campisi J, et al. (2010) The demographic and biomedical case for late-life interventions in aging. Sci Transl Med 2, $40 \mathrm{~cm} 21$.

12. Merry BJ, Kirk AJ \& Goyns MH (2008) Dietary lipoic acid supplementation can mimic or block the effect of dietary restriction on life span. Mech Ageing Dev 129, 341-348.

13. Minor RK, Smith DL Jr, Sossong AM, et al. (2010) Chronic ingestion of 2-deoxy-d-glucose induces cardiac vacuolization and increases mortality in rats. Toxicol Appl Pharmacol 243, 332-339.

14. Yu BP (1994) How diet influences the aging process of the rat. Proc Soc Exp Biol Med 205, 97-105.

15. Weindruch R (1996) The retardation of aging by caloric restriction: studies in rodents and primates. Toxicol Pathol 24, 742-745.

16. McCay CM, Crowell MF \& Maynard LA (1989) The effect of retarded growth upon the length of life span and upon the ultimate body size. 1935. Nutrition 5, 155-171; discussion 172.

17. Wu Z, Liu SQ \& Huang D (2013) Dietary restriction depends on nutrient composition to extend chronological lifespan in budding yeast Saccharomyces cerevisiae. PLOS ONE $\mathbf{8}$, e64448.

18. Lakowski B \& Hekimi S (1998) The genetics of caloric restriction in Caenorbabditis elegans. Proc Natl Acad Sci U S A 95, 13091-13096.

19. Min KJ, Yamamoto R, Buch S, et al. (2008) Drosophila lifespan control by dietary restriction independent of insulinlike signaling. Aging Cell 7, 199-206.

20. Weindruch R, Walford RL, Fligiel S, et al. (1986) The retardation of aging in mice by dietary restriction: longevity, cancer, immunity and lifetime energy intake. J Nutr 116, 641-654.

21. McShane TM \& Wise PM (1996) Life-long moderate caloric restriction prolongs reproductive life span in rats without interrupting estrous cyclicity: effects on the gonadotropinreleasing hormone/luteinizing hormone axis. Biol Reprod 54, 70-75.

22. Colman RJ, Anderson RM, Johnson SC, et al. (2009) Caloric restriction delays disease onset and mortality in rhesus monkeys. Science 325, 201-204.

23. McCay CM, Crowell MF \& Maynard LA (1935) The effect of retarded growth upon the length of life span and upon the ultimate body size. J Nutr 10, 63-79.

24. Swindell WR (2012) Dietary restriction in rats and mice: a meta-analysis and review of the evidence for genotypedependent effects on lifespan. Ageing Res Rev 11, 254-270. 
25. Sohal RS \& Forster MJ (2014) Caloric restriction and the aging process: a critique. Free Radic Biol Med 73, 366-382.

26. Mattison JA, Roth GS, Beasley TM, et al. (2012) Impact of caloric restriction on health and survival in rhesus monkeys from the NIA study. Nature 489, 318-321.

27. Walford RL, Harris SB \& Gunion MW (1992) The calorically restricted low-fat nutrient-dense diet in Biosphere 2 significantly lowers blood glucose, total leukocyte count, cholesterol, and blood pressure in humans. Proc Natl Acad Sci U S A 89, 11533-11537.

28. Walford RL, Mock D, Verdery R, et al. (2002) Calorie restriction in biosphere 2 , alterations in physiologic, hematologic, hormonal, and biochemical parameters in humans restricted for a 2-year period. J Gerontol A Biol Sci Med Sci 57, B211-B224.

29. Walford RL, Weber L \& Panov S (1995) Caloric restriction and aging as viewed from Biosphere 2. Receptor 5, 29-33.

30. Willcox BJ, Willcox DC, He Q, et al. (2006) Siblings of Okinawan centenarians share lifelong mortality advantages. J Gerontol A Biol Sci Med Sci 61, 345-354.

31. Willcox DC, Willcox BJ, Todoriki H, et al. (2009) The Okinawan diet: health implications of a low-calorie, nutrientdense, antioxidant-rich dietary pattern low in glycemic load. J Am Coll Nutr 28, Suppl, 500S-516S.

32. Lane MA, Mattison J, Ingram DK, et al. (2002) Caloric restriction and aging in primates: relevance to humans and possible CR mimetics. Microsc Res Tech 59, 335-338.

33. Duffy PH, Feuers RJ, Leakey JA, et al. (1989) Effect of chronic caloric restriction on physiological variables related to energy metabolism in the male Fischer 344 rat. Mech Ageing Dev 48, 117-133.

34. Mattison JA, Lane MA, Roth GS, et al. (2003) Calorie restriction in rhesus monkeys. Exp Gerontol 38, 35-46.

35. Chen D, Steele AD, Lindquist S, et al. (2005) Increase in activity during calorie restriction requires Sirt1. Science 310, 1641.

36. Speakman JR \& Mitchell SE (2011) Caloric restriction. Mol Aspects Med 32, 159-221.

37. Hwangbo DS, Gershman B, Tu MP, et al. (2004) Drosophila $\mathrm{dFOXO}$ controls lifespan and regulates insulin signalling in brain and fat body. Nature 429, 562-566.

38. Pires RC, Souza EE, Vanzela EC, et al. (2014) Short-term calorie restriction improves glucose homeostasis in old rats: involvement of AMPK. Appl Physiol Nutr Metab 39, 895-901.

39. Zhu M, Miura J, Lu LX, et al. (2004) Circulating adiponectin levels increase in rats on caloric restriction: the potential for insulin sensitization. Exp Gerontol 39, 1049-1059.

40. Weindruch R, Keenan KP, Carney JM, et al. (2001) Caloric restriction mimetics: metabolic interventions. $J$ Gerontol $A$ Biol Sci Med Sci 56, Spec no. 1, 20-33.

41. Lim EL, Hollingsworth KG, Aribisala BS, et al. (2011) Reversal of type 2 diabetes: normalisation of beta cell function in association with decreased pancreas and liver triacylglycerol. Diabetologia 54, 2506-2514.

42. Takatsu M, Nakashima C, Takahashi K, et al. (2013) Calorie restriction attenuates cardiac remodeling and diastolic dysfunction in a rat model of metabolic syndrome. Hypertension 62, 957-965.

43. Lezcano EJ, Inigo $\mathrm{P}$, Larraga $\mathrm{AM}$, et al. (2014) Caloric restriction or telmisartan control dyslipidemia and nephropathy in obese diabetic Zucker rats. Diabetol Metab Syndr 6, 10 .

44. Hagopian K, Ramsey JJ \& Weindruch R (2003) Caloric restriction increases gluconeogenic and transaminase enzyme activities in mouse liver. Exp Gerontol 38, $267-278$.
45. Feuers RJ, Duffy PH, Leakey JA, et al. (1989) Effect of chronic caloric restriction on hepatic enzymes of intermediary metabolism in the male Fischer 344 rat. Mech Ageing Dev 48, 179-189.

46. Hipkiss AR (2007) Dietary restriction, glycolysis, hormesis and ageing. Biogerontology 8, 221-224.

47. Anisimov VN, Berstein LM, Egormin PA, et al. (2005) Effect of metformin on life span and on the development of spontaneous mammary tumors in HER-2/neu transgenic mice. Exp Gerontol 40, 685-693.

48. Guo Z, Mitchell-Raymundo F, Yang H, et al. (2002) Dietary restriction reduces atherosclerosis and oxidative stress in the aorta of apolipoprotein E-deficient mice. Mech Ageing Dev 123, 1121-1131.

49. Yang F, Chu X, Yin M, et al. (2014) mTOR and autophagy in normal brain aging and caloric restriction ameliorating agerelated cognition deficits. Behav Brain Res 264, 82-90.

50. Weindruch R \& Walford RL (1982) Dietary restriction in mice beginning at 1 year of age: effect on life-span and spontaneous cancer incidence. Science 215, 1415-1418.

51. Hursting SD, Lavigne JA, Berrigan D, et al. (2003) Calorie restriction, aging, and cancer prevention: mechanisms of action and applicability to humans. Annu Rev Med 54, 131-152.

52. Sabatino F, Masoro EJ, McMahan CA, et al. (1991) Assessment of the role of the glucocorticoid system in aging processes and in the action of food restriction. J Gerontol $\mathbf{4 6}$, B171-B179.

53. Redman LM \& Ravussin E (2009) Endocrine alterations in response to calorie restriction in humans. Mol Cell Endocrinol 299, 129-136.

54. Cangemi R, Friedmann AJ, Holloszy JO, et al. (2010) Longterm effects of calorie restriction on serum sex-hormone concentrations in men. Aging Cell 9, 236-242.

55. Redman LM, Martin CK, Williamson DA, et al. (2008) Effect of caloric restriction in non-obese humans on physiological, psychological and behavioral outcomes. Physiol Behav $\mathbf{9 4}$, 643-648.

56. Smiarowska M, Safranow K, Dziedziejko V, et al. (2014) Association of plasma hormones, nutritional status, and stressful life events in anorexia nervosa patients. Postepy Hig Med Dosw (Online) 68, 162-171.

57. Sohal RS \& Weindruch R (1996) Oxidative stress, caloric restriction, and aging. Science $\mathbf{2 7 3}, 59-63$.

58. Roth GS, Handy AM, Mattison JA, et al. (2002) Effects of dietary caloric restriction and aging on thyroid hormones of rhesus monkeys. Horm Metab Res 34, 378-382.

59. Fontana L, Klein S, Holloszy JO, et al. (2006) Effect of longterm calorie restriction with adequate protein and micronutrients on thyroid hormones. J Clin Endocrinol Metab 91, 3232-3235.

60. Heilbronn LK, de Jonge L, Frisard MI, et al. (2006) Effect of 6-month calorie restriction on biomarkers of longevity, metabolic adaptation, and oxidative stress in overweight individuals: a randomized controlled trial. JAMA 295, 1539-1548.

61. Wikstrom L, Johansson C, Salto C, et al. (1998) Abnormal heart rate and body temperature in mice lacking thyroid hormone receptor $\alpha 1$. EMBO J 17, 455-461.

62. Brown-Borg HM, Borg KE, Meliska CJ, et al. (1996) Dwarf mice and the ageing process. Nature $\mathbf{3 8 4}, 33$.

63. Cadenas S, Buckingham JA, Samec S, et al. (1999) UCP2 and UCP3 rise in starved rat skeletal muscle but mitochondrial proton conductance is unchanged. FEBS Lett 462, 257-260.

64. Samec S, Seydoux J \& Dulloo AG (1998) Role of UCP homologues in skeletal muscles and brown adipose tissue: mediators 
of thermogenesis or regulators of lipids as fuel substrate? FASEB J 12, 715-724.

65. Duval C, Negre-Salvayre A, Dogilo A, et al. (2002) Increased reactive oxygen species production with antisense oligonucleotides directed against uncoupling protein 2 in murine endothelial cells. Biochem Cell Biol 80, 757-764.

66. Fontana L (2009) Neuroendocrine factors in the regulation of inflammation: excessive adiposity and calorie restriction. Exp Gerontol 44, 41-45.

67. Mattson MP (2008) Hormesis defined. Ageing Res Rev 7, 1-7.

68. Masoro EJ (2007) The role of hormesis in life extension by dietary restriction. Interdiscip Top Gerontol 35, 1-17.

69. Ristow M \& Zarse K (2010) How increased oxidative stress promotes longevity and metabolic health: the concept of mitochondrial hormesis (mitohormesis). Exp Gerontol 45 , 410-418.

70. Sharma $S$ \& Kaur G (2007) Intermittent dietary restriction as a practical intervention in aging. Ann NY Acad Sci 1114, 419-427.

71. Castello L, Froio T, Cavallini G, et al. (2005) Calorie restriction protects against age-related rat aorta sclerosis. FASEB J 19, 1863-1865.

72. Lakatta EG \& Levy D (2003) Arterial and cardiac aging: major shareholders in cardiovascular disease enterprises: Part I: aging arteries: a "set up" for vascular disease. Circulation 107, 139-146.

73. Valko M, Rhodes CJ, Moncol J, et al. (2006) Free radicals, metals and antioxidants in oxidative stress-induced cancer. Chem Biol Interact 160, 1-40.

74. Markesbery WR (1997) Oxidative stress hypothesis in Alzheimer's disease. Free Radic Biol Med 23, 134-147.

75. Browne SE, Ferrante RJ \& Beal MF (1999) Oxidative stress in Huntington's disease. Brain Pathol 9, 147-163.

76. Gredilla R \& Barja G (2005) Minireview: the role of oxidative stress in relation to caloric restriction and longevity. Endocrinology 146, 3713-3717.

77. Giller K, Huebbe P, Hennig S, et al. (2013) Beneficial effects of a 6-month dietary restriction are time-dependently abolished within 2 weeks or 6 months of refeeding-genome-wide transcriptome analysis in mouse liver. Free Radic Biol Med 61C, $170-178$.

78. Zhang Y \& Gordon GB (2004) A strategy for cancer prevention: stimulation of the Nrf2-ARE signaling pathway. Mol Cancer Ther 3, 885-893.

79. Martin-Montalvo A, Villalba JM, Navas P, et al. (2011) NRF2, cancer and calorie restriction. Oncogene 30, 505-520.

80. Chan K \& Kan YW (1999) Nrf2 is essential for protection against acute pulmonary injury in mice. Proc Natl Acad Sci U S A 96, 12731-12736.

81. Wasserman WW \& Fahl WE (1997) Functional antioxidant responsive elements. Proc Natl Acad Sci U S A 94, 5361-5366.

82. Suh JH, Shenvi SV, Dixon BM, et al. (2004) Decline in transcriptional activity of Nrf2 causes age-related loss of glutathione synthesis, which is reversible with lipoic acid. Proc Natl Acad Sci U S A 101, 3381-3386.

83. Shih PH \& Yen GC (2007) Differential expressions of antioxidant status in aging rats: the role of transcriptional factor Nrf2 and MAPK signaling pathway. Biogerontology 8, 71-80.

84. Pearson KJ, Lewis KN, Price NL, et al. (2008) Nrf2 mediates cancer protection but not prolongevity induced by caloric restriction. Proc Natl Acad Sci U S A 105, 2325-2330.

85. Sykiotis GP, Habeos IG, Samuelson AV, et al. (2011) The role of the antioxidant and longevity-promoting Nrf2 pathway in metabolic regulation. Current Opin Clin Nutr Metab Care 14, 41-48.
86. Faulks SC, Turner N, Else PL, et al. (2006) Calorie restriction in mice: effects on body composition, daily activity, metabolic rate, mitochondrial reactive oxygen species production, and membrane fatty acid composition. J Gerontol A Biol Sci Med Sci 61, 781-794.

87. Elchuri S, Oberley TD, Qi W, et al. (2005) CuZnSOD deficiency leads to persistent and widespread oxidative damage and hepatocarcinogenesis later in life. Oncogene 24, 367-380

88. Huang TT, Carlson EJ, Gillespie AM, et al. (2000) Ubiquitous overexpression of CuZn superoxide dismutase does not extend life span in mice. J Gerontol A Biol Sci Med Sci 55 , B5-B9.

89. Van Remmen H, Ikeno Y, Hamilton M, et al. (2003) Life-long reduction in MnSOD activity results in increased DNA damage and higher incidence of cancer but does not accelerate aging. Physiol Genomics 16, 29-37.

90. Lipman RD, Bronson RT, Wu D, et al. (1998) Disease incidence and longevity are unaltered by dietary antioxidant supplementation initiated during middle age in C57BL/6 mice. Mech Ageing Dev 103, 269-284.

91. Selman C, McLaren JS, Meyer C, et al. (2006) Life-long vitamin $\mathrm{C}$ supplementation in combination with cold exposure does not affect oxidative damage or lifespan in mice, but decreases expression of antioxidant protection genes. Mech Ageing Dev 127, 897-904.

92. Lee CK, Pugh TD, Klopp RG, et al. (2004) The impact of $\alpha$ lipoic acid, coenzyme Q10 and caloric restriction on life span and gene expression patterns in mice. Free Radic Biol Med 36, 1043-1057.

93. Schriner SE, Linford NJ, Martin GM, et al. (2005) Extension of murine life span by overexpression of catalase targeted to mitochondria. Science 308, 1909-1911.

94. Chung HY, Kim HJ, Jung KJ, et al. (2000) The inflammatory process in aging. Rev Clin Gerontol 10, 207-222.

95. Baldwin AS Jr (2001) Series introduction: the transcription factor NF-kB and human disease. J Clin Invest 107, 3-6.

96. Helenius M, Hanninen M, Lehtinen SK, et al. (1996) Aginginduced up-regulation of nuclear binding activities of oxidative stress responsive NF- $\kappa \mathrm{B}$ transcription factor in mouse cardiac muscle. J Mol Cell Cardiol 28, 487-498.

97. Chung HY, Kim HJ, Kim JW, et al. (2001) The inflammation hypothesis of aging: molecular modulation by calorie restriction. Ann N Y Acad Sci 928, 327-335.

98. Kang MJ, Kim HJ, Kim HK, et al. (2005) The effect of age and calorie restriction on HIF-1-responsive genes in aged liver. Biogerontology 6, 27-37.

99. Jung KJ, Lee EK, Kim JY, et al. (2009) Effect of short term calorie restriction on pro-inflammatory NF- $\mathrm{KB}$ and $\mathrm{AP}-1$ in aged rat kidney. Inflamm Res 58, 143-150.

100. Horrillo D, Gallardo N, Lauzurica N, et al. (2013) Development of liver fibrosis during aging: effects of caloric restriction. J Biol Regul Homeost Agents 27, 377-388.

101. Li N \& Karin M (1999) Is NF-кB the sensor of oxidative stress? FASEB J 13, 1137-1143.

102. Franceschi C \& Campisi J (2014) Chronic inflammation (inflammaging) and its potential contribution to ageassociated diseases. J Gerontol A Biol Sci Med Sci 69, Suppl. 1, S4-S9.

103. Varol C, Zvibel I, Spektor L, et al. (2014) Long-acting glucosedependent insulinotropic polypeptide ameliorates obesity-induced adipose tissue inflammation. I Immunol 193, 4002-4009.

104. Chung HY, Cesari M, Anton S, et al. (2009) Molecular inflammation: underpinnings of aging and age-related diseases. Ageing Res Rev 8, 18-30. 
105. Sung B, Park S, Yu BP, et al. (2004) Modulation of PPAR in aging, inflammation, and calorie restriction. J Gerontol A Biol Sci Med Sci 59, 997-1006.

106. Swindell WR (2009) Genes and gene expression modules associated with caloric restriction and aging in the laboratory mouse. BMC Genomics 10, 585.

107. Higami Y, Barger JL, Page GP, et al. (2006) Energy restriction lowers the expression of genes linked to inflammation, the cytoskeleton, the extracellular matrix, and angiogenesis in mouse adipose tissue. J Nutr 136, 343-352.

108. Kim JW, Zou Y, Yoon S, et al. (2004) Vascular aging: molecular modulation of the prostanoid cascade by calorie restriction. J Gerontol A Biol Sci Med Sci 59, B876-B885.

109. Cadenas E \& Davies KJ (2000) Mitochondrial free radical generation, oxidative stress, and aging. Free Radic Biol Med 29, 222-230.

110. Turrens JF (2003) Mitochondrial formation of reactive oxygen species. J Physiol 552, 335-344.

111. Murphy MP (2009) How mitochondria produce reactive oxygen species. Biochem J 417, 1-13.

112. Harper ME, Monemdjou S, Ramsey JJ, et al. (1998) Age-related increase in mitochondrial proton leak and decrease in ATP turnover reactions in mouse hepatocytes. Am J Physiol 275, E197-E206.

113. Hulbert AJ, Pamplona R, Buffenstein R, et al. (2007) Life and death: metabolic rate, membrane composition, and life span of animals. Physiol Rev 87, 1175-1213.

114. Alexeyev MF, Ledoux SP \& Wilson GL (2004) Mitochondrial DNA and aging. Clin Sci (Lond) 107, 355-364.

115. Pansarasa O, Bertorelli L, Vecchiet J, et al. (1999) Age-dependent changes of antioxidant activities and markers of free radical damage in human skeletal muscle. Free Radic Biol Med 27, 617-622.

116. Zhu J, Wang KZ \& Chu CT (2013) After the banquet: mitochondrial biogenesis, mitophagy, and cell survival Autophagy 9, 1663-1676.

117. Palikaras K \& Tavernarakis N (2014) Mitochondrial homeostasis: the interplay between mitophagy and mitochondrial biogenesis. Exp Gerontol 56, 182-188.

118. Dominy JE \& Puigserver P (2013) Mitochondrial biogenesis through activation of nuclear signaling proteins. Cold Spring Harb Perspect Biol 5, a015008.

119. Scarpulla RC (2008) Transcriptional paradigms in mammalian mitochondrial biogenesis and function. Physiol Rev 88, 611-638.

120. Picca A, Pesce V, Fracasso F, et al. (2013) Aging and calorie restriction oppositely affect mitochondrial biogenesis through TFAM binding at both origins of mitochondrial DNA replication in rat liver. PLOS ONE $\mathbf{8}$, e 74644.

121. Srivastava S, Diaz F, Iommarini L, et al. (2009) PGC- $1 \alpha / \beta$ induced expression partially compensates for respiratory chain defects in cells from patients with mitochondrial disorders. Human Mol Genet 18, 1805-1812.

122. Cantó C \& Auwerx J (2009) PGC-1 $\alpha$, SIRT1 and AMPK, an energy sensing network that controls energy expenditure. Curr Opin Lipidol 20, 98-105.

123. Massey AC, Kiffin R \& Cuervo AM (2006) Autophagic defects in aging: looking for an 'emergency exit'? Cell Cycle 5, 1292-1296.

124. Miwa S, Lawless C \& von Zglinicki T (2008) Mitochondrial turnover in liver is fast in vivo and is accelerated by dietary restriction: application of a simple dynamic model. Aging Cell 7, 920-923.

125. Parzych KR \& Klionsky DJ (2014) An overview of autophagy: morphology, mechanism, and regulation. Antioxid Redox Signal 20, 460-473.
126. Ravikumar B, Sarkar S, Davies JE, et al. (2010) Regulation of mammalian autophagy in physiology and pathophysiology. Physiol Rev 90, 1383-1435.

127. Yang Z \& Klionsky DJ (2009) An overview of the molecular mechanism of autophagy. Curr Top Microbiol Immunol 335 , $1-32$.

128. Levine B \& Klionsky DJ (2004) Development by self-digestion: molecular mechanisms and biological functions of autophagy. Dev Cell 6, 463-477.

129. Powell MJ, Casimiro MC, Cordon-Cardo C, et al. (2011) Disruption of a Sirt1-dependent autophagy checkpoint in the prostate results in prostatic intraepithelial neoplasia lesion formation. Cancer Res 71, 964-975.

130. Fleming A, Noda T, Yoshimori T, et al. (2011) Chemical modulators of autophagy as biological probes and potential therapeutics. Nat Chem Biol 7, 9-17.

131. Alers S, Loffler AS, Wesselborg S, et al. (2012) Role of AMPKmTOR-Ulk1/2 in the regulation of autophagy: cross talk, shortcuts, and feedbacks. Mol Cell Biol 32, 2-11.

132. Bergamini E, Cavallini G, Donati A, et al. (2007) The role of autophagy in aging: its essential part in the anti-aging mechanism of caloric restriction. Ann NY Acad Sci 1114, 69-78.

133. Eisenberg T, Knauer H, Schauer A, et al. (2009) Induction of autophagy by spermidine promotes longevity. Nat Cell Biol 11, $1305-1314$.

134. Rubinsztein DC, Marino G \& Kroemer G (2011) Autophagy and aging. Cell 146, 682-695.

135. LaRocca TJ, Henson GD, Thorburn A, et al. (2012) Translational evidence that impaired autophagy contributes to arterial ageing. J Physiol 590, 3305-3316.

136. Donati A (2006) The involvement of macroautophagy in aging and anti-aging interventions. Mol Aspects Med 27, 455-470.

137. Salminen A, Kaarniranta K, Kauppinen A, et al. (2013) Impaired autophagy and APP processing in Alzheimer's disease: the potential role of Beclin 1 interacto. Prog Neurobiol 106-107, 33-54.

138. Wolfe DM, Lee JH, Kumar A, et al. (2013) Autophagy failure in Alzheimer's disease and the role of defective lysosomal acidificati. Eur J Neurosci 37, 1949-1961.

139. Lynch-Day MA, Mao K, Wang K, et al. (2012) The role of autophagy in Parkinson's disease. Cold Spring Harb Perspect Med 2, a009357.

140. Cortes CJ \& La Spada AR (2014) The many faces of autophagy dysfunction in Huntington's disease: from mechanism to therapy. Drug Discov Today 19, 963-971.

141. Hardie DG (2007) AMP-activated/SNF1 protein kinases: conserved guardians of cellular energy. Nat Rev Mol Cell Biol 8, 774-785.

142. Zhu Z, Jiang W, McGinley JN, et al. (2005) 2-Deoxyglucose as an energy restriction mimetic agent: effects on mammary carcinogenesis and on mammary tumor cell growth in vitro. Cancer Res 65, 7023-7030.

143. Lee IH, Cao L, Mostoslavsky R, et al. (2008) A role for the NAD-dependent deacetylase Sirt1 in the regulation of autophagy. Proc Natl Acad Sci U S A 105, 3374-3379.

144. Pimentel GD, Ropelle ER, Rocha GZ, et al. (2013) The role of neuronal AMPK as a mediator of nutritional regulation of food intake and energy homeostasis. Metabolism 62, 171-178.

145. Greer EL, Oskoui PR, Banko MR, et al. (2007) The energy sensor AMP-activated protein kinase directly regulates the mammalian FOXO3 transcription factor. $J$ Biol Chem 282, 30107-30119.

146. Jager S, Handschin C, St-Pierre J, et al. (2007) AMP-activated protein kinase (AMPK) action in skeletal muscle via direct 
phosphorylation of PGC-1 $\alpha$. Proc Natl Acad Sci U S A 104, 12017-12022.

147. Canto C, Jiang LQ, Deshmukh AS, et al. (2010) Interdependence of AMPK and SIRT1 for metabolic adaptation to fasting and exercise in skeletal muscle. Cell Metab 11, 213-219.

148. Tohyama D \& Yamaguchi A (2010) A critical role of SNF1A/ dAMPK $\alpha$ (Drosophila AMP-activated protein kinase $\alpha$ ) in muscle on longevity and stress resistance in Drosophila melanogaster. Biochem Biophys Res Comm 394, 112-118.

149. Apfeld J, O'Connor G, McDonagh T, et al. (2004) The AMP-activated protein kinase AAK-2 links energy levels and insulin-like signals to lifespan in C. elegans. Genes Dev 18, 3004-3009.

150. Palacios OM, Carmona JJ, Michan S, et al. (2009) Diet and exercise signals regulate SIRT3 and activate AMPK and PGC-1 $\alpha$ in skeletal muscle. Aging 1, 771-783.

151. Edwards AG, Donato AJ, Lesniewski LA, et al. (2010) Lifelong caloric restriction elicits pronounced protection of the aged myocardium: a role for AMPK. Mech Ageing Dev 131, 739-742.

152. Miller BF, Robinson MM, Bruss MD, et al. (2012) A comprehensive assessment of mitochondrial protein synthesis and cellular proliferation with age and caloric restriction. Aging Cell 11, 150-161.

153. Gonzalez AA, Kumar R, Mulligan JD, et al. (2004) Metabolic adaptations to fasting and chronic caloric restriction in heart, muscle, and liver do not include changes in AMPK activity. Am J Physiol Endocrinol Metab 287, E1032-E1037.

154. Um JH, Park SJ, Kang H, et al. (2010) AMP-activated protein kinase-deficient mice are resistant to the metabolic effects of resveratrol. Diabetes 59, 554-563.

155. Price NL, Gomes AP, Ling AJ, et al. (2012) SIRT1 is required for AMPK activation and the beneficial effects of resveratrol on mitochondrial function. Cell Metab 15, 675-690.

156. Han L, Zhao G, Wang H, et al. (2014) Calorie restriction upregulated sirtuin 1 by attenuating its ubiquitin degradation in cancer cells. Clin Exp Pharmacol Physiol 41, 165-168.

157. Silvestre MF, Viollet B, Caton PW, et al. (2014) The AMPKSIRT signaling network regulates glucose tolerance under calorie restriction conditions. Life Sci 100, 55-60.

158. Yu W, Zhou HF, Lin RB, et al. (2014) Short-term calorie restriction activates SIRT14 and 7 in cardiomyocytes in vivo and in vitro. Mol Med Rep 9, 1218-1224.

159. Lagouge M, Argmann C, Gerhart-Hines Z, et al. (2006) Resveratrol improves mitochondrial function and protects against metabolic disease by activating SIRT1 and PGC- $1 \alpha$. Cell 127, 1109-1122.

160. Morselli E, Maiuri MC, Markaki M, et al. (2010) Caloric restriction and resveratrol promote longevity through the sirtuin-1-dependent induction of autophagy. Cell Death Dis $\mathbf{1}$, e10.

161. Guarente L (2006) Sirtuins as potential targets for metabolic syndrome. Nature 444, 868-874.

162. Hoff KG \& Wolberger C (2005) Getting a grip on O-acetyl-ADP-ribose. Nat Struct Mol Biol 12, 560-561.

163. Vaquero A, Scher M, Lee D, et al. (2004) Human SirT1 interacts with histone $\mathrm{H} 1$ and promotes formation of facultative heterochromatin. Mol Cell 16, 93-105.

164. Cameron EE, Bachman KE, Myöhänen S, et al. (1999) Synergy of demethylation and histone deacetylase inhibition in the re-expression of genes silenced in cancer. Nat Genet 21, 103-107.

165. Rodgers JT, Lerin C, Haas W, et al. (2005) Nutrient control of glucose homeostasis through a complex of PGC- $1 \alpha$ and SIRT1. Nature 434, 113-118.
166. Lopez-Lluch G, Irusta PM, Navas P, et al. (2008) Mitochondrial biogenesis and healthy aging. Exp Gerontol 43, 813-819.

167. Morselli E, Maiuri MC, Markaki M, et al. (2010) The life spanprolonging effect of sirtuin-1 is mediated by autophagy. Autophagy 6, 186-188.

168. Kaeberlein M, McVey M \& Guarente L (1999) The SIR2/3/4 complex and SIR2 alone promote longevity in Saccharomyces cerevisiae by two different mechanisms. Genes Dev 13, 2570-2580

169. Tissenbaum HA \& Guarente L (2001) Increased dosage of a sir-2 gene extends lifespan in Caenorhabditis elegans. Nature 410, 227-230.

170. Wood JG, Rogina B, Lavu S, et al. (2004) Sirtuin activators mimic caloric restriction and delay ageing in metazoans. Nature 430, 686-689

171. Satoh A, Brace CS, Rensing N, et al. (2013) Sirt1 extends life span and delays aging in mice through the regulation of $\mathrm{Nk} 2$ homeobox 1 in the DMH and LH. Cell Metab 18, 416-430.

172. Liang F, Kume S \& Koya D (2009) SIRT1 and insulin resistance. Nat Rev Endocrinol 5, 367-373.

173. Pfluger PT, Herranz D, Velasco-Miguel S, et al. (2008) Sirt1 protects against high-fat diet-induced metabolic damage. Proc Natl Acad Sci U S A 105, 9793-9798.

174. Herranz D, Muñoz-Martin M, Cañamero M, et al. (2010) Sirt1 improves healthy ageing and protects from metabolic syndrome-associated cancer. Nat Commun 1, 3.

175. Tamori Y, Masugi J, Nishino N, et al. (2002) Role of peroxisome proliferator-activated receptor- $\gamma$ in maintenance of the characteristics of mature 3T3-L1 adipocytes. Diabetes $\mathbf{5 1}$, 2045-2055.

176. Picard F, Kurtev M, Chung N, et al. (2004) Sirt1 promotes fat mobilization in white adipocytes by repressing PPAR- $\gamma$. Nature 429, 771-776.

177. Jiang JC, Wawryn J, Shantha Kumara HM, et al. (2002) Distinct roles of processes modulated by histone deacetylases Rpd3p, Hda1p, and Sir2p in life extension by caloric restriction in yeast. Exp Gerontol 37, 1023-1030.

178. Smith DL Jr, McClure JM, Matecic M, et al. (2007) Calorie restriction extends the chronological lifespan of Saccharomyces cerevisiae independently of the sirtuins. Aging Cell $\mathbf{6}$, 649-662.

179. Kanfi Y, Peshti V, Gozlan YM, et al. (2008) Regulation of SIRT1 protein levels by nutrient availability. FEBS Lett $\mathbf{5 8 2}$, $2417-2423$

180. Lopez-Lluch G, Hunt N, Jones B, et al. (2006) Calorie restriction induces mitochondrial biogenesis and bioenergetic efficiency. Proc Natl Acad Sci U S A 103, 1768-1773.

181. Hepple RT, Baker DJ, McConkey M, et al. (2006) Caloric restriction protects mitochondrial function with aging in skeletal and cardiac muscles. Rejuvenation Res 9, 219-222.

182. Anderson R \& Prolla T (2009) PGC-1 $\alpha$ in aging and anti-aging interventions. Biochim Biophys Acta 1790, 1059-1066.

183. Lin J, Wu H, Tarr PT, et al. (2002) Transcriptional co-activator PGC- $1 \alpha$ drives the formation of slow-twitch muscle fibres. Nature 418, 797-801

184. Puigserver P, Wu Z, Park CW, et al. (1998) A cold-inducible coactivator of nuclear receptors linked to adaptive thermogenesis. Cell 92, 829-839.

185. Lee CK, Allison DB, Brand J, et al. (2002) Transcriptional profiles associated with aging and middle age-onset caloric restriction in mouse hearts. Proc Natl Acad Sci U S A 99 , 14988-14993.

186. Hancock CR, Han DH, Higashida K, et al. (2011) Does calorie restriction induce mitochondrial biogenesis? A reevaluation. FASEB J 25, 785-791. 
187. Calnan DR \& Brunet A (2008) The FoxO code. Oncogene 27 2276-2288.

188. Finkel T, Deng CX \& Mostoslavsky R (2009) Recent progress in the biology and physiology of sirtuins. Nature $\mathbf{4 6 0}$, 587-591.

189. Brunet A, Sweeney LB, Sturgill JF, et al. (2004) Stress-dependent regulation of FOXO transcription factors by the SIRT1 deacetylase. Science 303, 2011-2015.

190. Zhao Y, Yang J, Liao W, et al. (2010) Cytosolic FoxO1 is essential for the induction of autophagy and tumour suppressor activity. Nat Cell Biol 12, 665-675.

191. Plas DR \& Thompson CB (2003) Akt activation promotes degradation of tuberin and $\mathrm{FOXO} 3 \mathrm{a}$ via the proteasome. J Biol Chem 278, 12361-12366.

192. Tazearslan C, Cho M \& Suh Y (2012) Discovery of functional gene variants associated with human longevity: opportunities and challenges. I Gerontol A Biol Sci Med Sci 67, 376-383.

193. Bluher M, Kahn BB \& Kahn CR (2003) Extended longevity in mice lacking the insulin receptor in adipose tissue. Science 299, 572-574

194. Berryman DE, Christiansen JS, Johannsson G, et al. (2008) Role of the GH/IGF-1 axis in lifespan and healthspan: lessons from animal models. Growth Horm IGF Res 18, 455-471.

195. Dunn SE, Kari FW, French J, et al. (1997) Dietary restriction reduces insulin-like growth factor I levels, which modulates apoptosis, cell proliferation, and tumor progression in p53-deficient mice. Cancer Res 57, 4667-4672.

196. Steger RW, Bartke A \& Cecim M (1993) Premature ageing in transgenic mice expressing different growth hormone genes. J Reprod Fertil Suppl 46, 61-75.

197. Suh Y, Atzmon G, Cho MO, et al. (2008) Functionally significant insulin-like growth factor I receptor mutations in centenarians. Proc Natl Acad Sci U S A 105, 3438-3442.

198. Holzenberger M, Dupont J, Ducos B, et al. (2003) IGF-1 receptor regulates lifespan and resistance to oxidative stress in mice. Nature 421, 182-187.

199. Ikeno Y, Bronson RT, Hubbard GB, et al. (2003) Delayed occurrence of fatal neoplastic diseases in Ames dwarf mice: correlation to extended longevity. J Gerontol A Biol Sci Med Sci 58, 291-296.

200. Milman S, Atzmon G, Huffman DM, et al. (2014) Low insulinlike growth factor-1 level predicts survival in humans with exceptional longevity. Aging Cell 13, 769-771.

201. Facchini FS, Hua NW, Reaven GM, et al. (2000) Hyperinsulinemia: the missing link among oxidative stress and agerelated diseases? Free Radic Biol Med 29, 1302-1306.

202. Liu HY, Han J, Cao SY, et al. (2009) Hepatic autophagy is suppressed in the presence of insulin resistance and hyperinsulinemia: inhibition of FoxO1-dependent expression of key autophagy genes by insulin. J Biol Chem 284, 31484-31492.

203. Fleming-Waddell JN, Olbricht GR, Taxis TM, et al. (2009) Effect of DLK1 and RTL1 but not MEG3 or MEG8 on muscle gene expression in Callipyge lambs. PloS ONE 4, e7399.

204. Hay N \& Sonenberg N (2004) Upstream and downstream of mTOR. Genes Dev 18, 1926-1945.

205. Ciuffreda L, Di Sanza C, Incani UC, et al. (2010) The mTOR pathway: a new target in cancer therapy. Curr Cancer Drug Targets 10, 484-495.

206. Powers RW III, Kaeberlein M, Caldwell SD, et al. (2006) Extension of chronological life span in yeast by decreased TOR pathway signaling. Genes Dev 20, 174-184.

207. Kaeberlein M, Powers RW III, Steffen KK, et al. (2005) Regulation of yeast replicative life span by TOR and Sch9 in response to nutrients. Science 310, 1193-1196.
208. Jia K, Chen D \& Riddle DL (2004) The TOR pathway interacts with the insulin signaling pathway to regulate C. elegans larval development, metabolism and life span. Development 131, 3897-3906.

209. Vellai T, Takacs-Vellai K, Zhang Y, et al. (2003) Genetics: influence of TOR kinase on lifespan in C. elegans. Nature 426, 620 .

210. Kapahi P, Zid BM, Harper T, et al. (2004) Regulation of lifespan in Drosophila by modulation of genes in the TOR signaling pathway. Curr Biol 14, 885-890.

211. Sharp ZD \& Bartke A (2005) Evidence for down-regulation of phosphoinositide 3-kinase/Akt/mammalian target of rapamycin ( $\mathrm{PI} 3 \mathrm{~K} / \mathrm{Akt} / \mathrm{mTOR})$-dependent translation regulatory signaling pathways in Ames dwarf mice. J Gerontol A Biol Sci Med Sci 60, 293-300.

212. Sun L, Sadighi Akha AA, Miller RA, et al. (2009) Life-span extension in mice by preweaning food restriction and by methionine restriction in middle age. J Gerontol A Biol Sci Med Sci 64, 711-722.

213. Ravikumar B, Vacher C, Berger Z, et al. (2004) Inhibition of mTOR induces autophagy and reduces toxicity of polyglutamine expansions in fly and mouse models of Huntington disease. Nat Genet 36, 585-595.

214. Toth ML, Sigmond T, Borsos E, et al. (2008) Longevity pathways converge on autophagy genes to regulate life span in Caenorhabditis elegans. Autophagy $\mathbf{4}$, 330-338.

215. Duffy PH, Seng JE, Lewis SM, et al. (2001) The effects of different levels of dietary restriction on aging and survival in the Sprague-Dawley rat: implications for chronic studies. Aging (Milano) 13, 263-272.

216. Villareal DT, Kotyk JJ, Armamento-Villareal RC, et al. (2011) Reduced bone mineral density is not associated with significantly reduced bone quality in men and women practicing long-term calorie restriction with adequate nutrition. Aging Cell 10, 96-102.

217. Hunt ND, Li GD, Zhu M, et al. (2012) Effect of calorie restriction and refeeding on skin wound healing in the rat. Age (Dordr) 34, 1453-1458.

218. Goldberg EL, Romero-Aleshire MJ, Renkema KR, et al. (2015) Lifespan-extending caloric restriction or mTOR inhibition impair adaptive immunity of old mice by distinct mechanisms. Aging Cell 14, 130-138.

219. Goodrick CL, Ingram DK, Reynolds MA, et al. (1982) Effects of intermittent feeding upon growth and life span in rats. Gerontology 28, 233-241.

220. Johnson JB, Laub DR \& John S (2006) The effect on health of alternate day calorie restriction: eating less and more than needed on alternate days prolongs life. Med Hypotheses $\mathbf{6 7}$, 209-211.

221. Descamps O, Riondel J, Ducros V, et al. (2005) Mitochondrial production of reactive oxygen species and incidence of ageassociated lymphoma in OF1 mice: effect of alternate-day fasting. Mech Ageing Dev 126, 1185-1191.

222. Ahmet I, Wan R, Mattson MP, et al. (2005) Cardioprotection by intermittent fasting in rats. Circulation 112, 3115-3121.

223. Mager DE, Wan R, Brown M, et al. (2006) Caloric restriction and intermittent fasting alter spectral measures of heart rate and blood pressure variability in rats. FASEB $J \mathbf{2 0}$, 631-637.

224. Chung KW, Kim DH, Park MH, et al. (2013) Recent advances in calorie restriction research on aging. Exp Gerontol 48, 1049-1053.

225. Ingram DK, Zhu M, Mamczarz J, et al. (2006) Calorie restriction mimetics: an emerging research field. Aging Cell 5, 97-108. 
226. Smith DL Jr, Nagy TR \& Allison DB (2010) Calorie restriction: what recent results suggest for the future of ageing research. Eur J Clin Invest 40, 440-450.

227. Selman C (2014) Dietary restriction and the pursuit of effective mimetics. Proc Nutr Soc 73, 260-270.

228. Lane MA, Roth GS \& Ingram DK (2007) Caloric restriction mimetics: a novel approach for biogerontology. Methods Mol Biol 371, 143-149.

229. Weimer S, Priebs J, Kuhlow D, et al. (2014) D-Glucosamine supplementation extends life span of nematodes and of ageing mice. Nat Comm 5, 3563.

230. Ingram DK, Anson RM, de Cabo R, et al. (2004) Development of calorie restriction mimetics as a prolongevity strategy. Ann N Y Acad Sci 1019, 412-423.

231. Smith DL Jr, Elam CF Jr, Mattison JA, et al. (2010) Metformin supplementation and life span in Fischer-344 rats. J Gerontol A Biol Sci Med Sci 65, 468-474.

232. Ingram DK \& Roth GS (2015) Calorie restriction mimetics: can you have your cake and eat it, too? Ageing Res Rev 20C, 46-62.

233. Donati A, Cavallini G, Carresi C, et al. (2004) Anti-aging effects of anti-lipolytic drugs. Exp Gerontol 39, 1061-1067.

234. Straniero S, Cavallini G, Donati A, et al. (2009) Stimulation of autophagy by antilipolytic drugs may rescue rodents from age-associated hypercholesterolemia. Rejuvenation Res $\mathbf{1 2}$, $77-84$.

235. Alcaín FJ \& Villalba JM (2009) Sirtuin activators. Expert Opin Ther Pat 19, 403-414.

236. Marino G, Pietrocola F, Madeo F, et al. (2014) Caloric restriction mimetics: natural/physiological pharmacological autophagy inducers. Autophagy 10, 1879-1882.

237. Navarro-Alarcón M, Ruiz-Ojeda FJ, Blanca-Herrera RM, et al. (2014) Melatonin and metabolic regulation: a review. Food Funct 5, 2806-2832.

238. Lane MA, Ingram DK \& Roth GS (1998) 2-Deoxy-D-glucose feeding in rats mimics physiologic effects of calorie restriction. J Anti Aging Med 1, 327-337.

239. Brown J (1962) Effects of 2-deoxyglucose on carbohydrate metablism: review of the literature and studies in the rat. Metabolism 11, 1098-1112.

240. Yao J, Chen S, Mao Z, et al. (2011) 2-Deoxy-D-glucose treatment induces ketogenesis, sustains mitochondrial function, and reduces pathology in female mouse model of Alzheimer's disea. PloS ONE 6, e21788.

241. Wan R, Camandola S \& Mattson MP (2003) Intermittent fasting and dietary supplementation with 2-deoxy-D-glucose improve functional and metabolic cardiovascular risk factors in rats. FASEB J 17, 1133-1134.

242. Ingram DK \& Roth GS (2011) Glycolytic inhibition as a strategy for developing calorie restriction mimetics. Exp Gerontol 46, 148-154.

243. Lee J, Bruce-Keller AJ, Kruman Y, et al. (1999) 2-Deoxy-Dglucose protects hippocampal neurons against excitotoxic and oxidative injury: evidence for the involvement of stress proteins. J Neurosci Res 57, 48-61.

244. Canto C, Gerhart-Hines Z, Feige JN, et al. (2009) AMPK regulates energy expenditure by modulating NAD+ metabolism and SIRT1 activi. Nature 458, 1056-1060.

245. Schulz TJ, Zarse K, Voigt A, et al. (2007) Glucose restriction extends Caenorhabditis elegans life span by inducing mitochondrial respiration and increasing oxidative stress. Cell Metab 6, 280-293.

246. Correia S, Carvalho C, Santos MS, et al. (2008) Mechanisms of action of metformin in type 2 diabetes and associated complications: an overview. Mini Rev Med Chem 8, $1343-1354$.
247. Radziuk J, Bailey CJ, Wiernsperger NF, et al. (2003) Metformin and its liver targets in the treatment of type 2 diabetes. Curr Drug Targets Immune Endocr Metabol Disord 3, 151-169.

248. Testa G, Biasi F, Poli G, et al. (2014) Calorie restriction and dietary restriction mimetics: a strategy for improving healthy aging and longevity. Curr Pharm Des 20, 2950-2977.

249. Libby G, Donnelly LA, Donnan PT, et al. (2009) New users of metformin are at low risk of incident cancer: a cohort study among people with type 2 diabetes. Diabetes Care $\mathbf{3 2}$, $1620-1625$.

250. Berstein LM (2012) Metformin in obesity, cancer and aging: addressing controversies. Aging 4, 320-329.

251. Nagi DK \& Yudkin JS (1993) Effects of metformin on insulin resistance, risk factors for cardiovascular disease, and plasminogen activator inhibitor in NIDDM subjects. A study of two ethnic groups. Diabetes Care 16, 621-629.

252. Anisimov VN, Berstein LM, Egormin PA, et al. (2008) Metformin slows down aging and extends life span of female SHR mice. Cell Cycle 7, 2769-2773.

253. Ben Sahra I, Le Marchand-Brustel Y, Tanti JF, et al. (2010) Metformin in cancer therapy: a new perspective for an old antidiabetic drug? Mol Cancer Ther 9, 1092-1099.

254. Dhahbi JM, Mote PL, Fahy GM, et al. (2005) Identification of potential caloric restriction mimetics by microarray profiling. Physiol Genomics 23, 343-350.

255. Onken B \& Driscoll M (2010) Metformin induces a dietary restriction-like state and the oxidative stress response to extend C. elegans healthspan via AMPK, LKB1, and SKN-1. PloS ONE 5, e8758.

256. Holst H, Eldrup E, Guldstad NH, et al. (2012) Metformin associated with lactic acidosis in treatment of type 2 diabetes (article in Danish). Ugeskr Laeger 174, 1598-1602.

257. Salpeter SR, Greyber E, Pasternak GA, et al. (2003) Risk of fatal and nonfatal lactic acidosis with metformin use in type 2 diabetes mellitus: systematic review and meta-analysis. Arch Intern Med 163, 2594-2602.

258. Kruse JA (2004) Review: metformin does not increase risk for lactic acidosis or increase lactate levels in type 2 diabetes. ACP J Club 141, 7.

259. Nisbet JC, Sturtevant JM \& Prins JB (2004) Metformin and serious adverse effects. MJ Aust 180, 53-54.

260. Wullschleger S, Loewith R \& Hall MN (2006) TOR signaling in growth and metabolism. Cell 124, 471-484

261. Garber K (2001) Rapamycin's resurrection: a new way to target the cancer cell cyc. J Natl Cancer Inst 93, 1517-1519.

262. Crespo JL \& Hall MN (2002) Elucidating TOR signaling and rapamycin action: lessons from Saccharomyces cerevisiae. Microbiol Mol Biol Rev 66, 579-591, table of contents.

263. Heitman J, Movva NR \& Hall MN (1991) Targets for cell cycle arrest by the immunosuppressant rapamycin in yeast. Science 253, 905-909.

264. Alvers AL, Wood MS, Hu D, et al. (2009) Autophagy is required for extension of yeast chronological life span by rapamycin. Autophagy 5, 847-849.

265. Fontana L, Partridge L \& Longo VD (2010) Extending healthy life span - from yeast to humans. Science 328, 321-326.

266. Cuervo AM (2008) Autophagy and aging: keeping that old broom working. Trends Genet 24, 604-612.

267. Harrison DE, Strong R, Sharp ZD, et al. (2009) Rapamycin fed late in life extends lifespan in genetically heterogeneous mice. Nature 460, 392-395.

268. Miller RA, Harrison DE, Astle CM, et al. (2011) Rapamycin, but not resveratrol or simvastatin, extends life span of genetically heterogeneous mice. J Gerontol A Biol Sci Med Sci 66, 191-201. 
269. Stanfel MN, Shamieh LS, Kaeberlein M, et al. (2009) The TOR pathway comes of age. Biochim Biophys Acta $\mathbf{1 7 9 0 ,}$ 1067-1074.

270. Mizushima N (2010) The role of the Atg1/ULK1 complex in autophagy regulation. Curr Opin Cell Biol 22, 132-139.

271. Calabrese V, Cornelius C, Dinkova-Kostova AT, et al. (2012) Cellular stress responses, hormetic phytochemicals and vitagenes in aging and longevity. Biochim Biophys Acta 1822, 753-783

272. Bove J, Martinez-Vicente M \& Vila M (2011) Fighting neurodegeneration with rapamycin: mechanistic insights. Nat Rev Neurosci 12, 437-452.

273. Blagosklonny MV (2009) Validation of anti-aging drugs by treating age-related diseases. Aging 1, 281-288.

274. Afaq F \& Mukhtar H (2006) Botanical antioxidants in the prevention of photocarcinogenesis and photoaging. Exp Dermatol 15, 678-684.

275. Agarwal B \& Baur JA (2011) Resveratrol and life extension. Ann N Y Acad Sci 1215, 138-143.

276. Vuong TV, Franco C \& Zhang W (2014) Treatment strategies for high resveratrol induction in Vitis vinifera L. cell suspension culture. Biotechnol Rep 1-2, 15-21.

277. Baur JA \& Sinclair DA (2006) Therapeutic potential of resveratrol: the in vivo evidence. Nat Rev Drug Discov 5, 493-506.

278. Zou S, Carey JR, Liedo P, et al. (2009) The prolongevity effect of resveratrol depends on dietary composition and calorie intake in a tephritid fruit fly. Exp Gerontol 44, 472-476.

279. Howitz KT, Bitterman KJ, Cohen HY, et al. (2003) Small molecule activators of sirtuins extend Saccharomyces cerevisiae lifespan. Nature 425, 191-196.

280. Valenzano DR, Terzibasi E, Genade T, et al. (2006) Resveratrol prolongs lifespan and retards the onset of agerelated markers in a short-lived vertebrate. Curr Biol 16, 296-300.

281. Baur JA, Pearson KJ, Price NL, et al. (2006) Resveratrol improves health and survival of mice on a high-calorie diet. Nature 444, 337-342.

282. Bass TM, Weinkove D, Houthoofd K, et al. (2007) Effects of resveratrol on lifespan in Drosophila melanogaster and Caenorhabditis elegans. Mech Ageing Dev 128, 546-552.

283. Pearson KJ, Baur JA, Lewis KN, et al. (2008) Resveratrol delays age-related deterioration and mimics transcriptional aspects of dietary restriction without extending life span. Cell Metab 8, 157-168.

284. Strong R, Miller RA, Astle CM, et al. (2013) Evaluation of resveratrol, green tea extract, curcumin, oxaloacetic acid, and medium-chain triglyceride oil on life span of genetically heterogeneous mice. J Gerontol A Biol Sci Med Sci 68, 6-16.

285. Pan M, Yuan H, Brent M, et al. (2012) SIRT1 contains N- and C-terminal regions that potentiate deacetylase activity. $J$ Biol Chem 287, 2468-2476.

286. Pacholec M, Bleasdale JE, Chrunyk B, et al. (2010) SRT1720, SRT2183, SRT1460, and resveratrol are not direct activators of SIRT1. J Biol Chem 285, 8340-8351.

287. Kaeberlein M, McDonagh T, Heltweg B, et al. (2005) Substrate-specific activation of sirtuins by resveratrol. $J$ Biol Chem 280, 17038-17045.

288. Park SJ, Ahmad F, Philp A, et al. (2012) Resveratrol ameliorates aging-related metabolic phenotypes by inhibiting CAMP phosphodiesterases. Cell 148, 421-433.

289. Sajish M \& Schimmel P (2015) A human tRNA synthetase is a potent PARP1-activating effector target for resveratrol. Nature 519, 370-373.

290. Crowell JA, Korytko PJ, Morrissey RL, et al. (2004) Resveratrol-associated renal toxicity. Toxicol Sci 82, 614-619.
291. Soda K, Dobashi Y, Kano Y, et al. (2009) Polyamine-rich food decreases age-associated pathology and mortality in aged mice. Exp Gerontol 44, 727-732.

292. Scalabrino G \& Ferioli ME (1984) Polyamines in mammalian ageing: an oncological problem, too? A review. Mech Ageing Dev 26, 149-164.

293. Paik MJ, Ahn YH, Lee PH, et al. (2010) Polyamine patterns in the cerebrospinal fluid of patients with Parkinson's disease and multiple system atrop. Clin Chim Acta 411, 1532-1535.

294. Jin HT, Raty S, Minkkinen M, et al. (2009) Changes in blood polyamine levels in human acute pancreatitis. Scand J Gastroenterol 44, 1004-1011.

295. ter Steege JC, Forget PP \& Buurman WA (1999) Oral spermine administration inhibits NO-mediated intestinal damage and levels of systemic inflammatory mediators in a mouse endotoxin model. Shock 11, 115-119.

296. Soda K, Kano Y, Nakamura T, et al. (2005) Spermine, a natural polyamine, suppresses LFA-1 expression on human lymphocyte. J Immunol 175, 237-245.

297. Seidl R, Beninati S, Cairns N, et al. (1996) Polyamines in frontal cortex of patients with Down syndrome and Alzheimer disease. Neurosci Lett 206, 193-195.

298. Guo X, Harada C, Namekata K, et al. (2011) Spermidine alleviates severity of murine experimental autoimmune encephalomyelitis. Invest Ophthalmol Vis Sci 52, 2696-2703.

299. Zhu S, Ashok M, Li J, et al. (2009) Spermine protects mice against lethal sepsis partly by attenuating surrogate inflammatory markers. Mol Med 15, 275-282.

300. Morgan DM (1998) Polyamines. An introduction. Methods Mol Biol 79, 3-30.

301. Minois N, Carmona-Gutierrez D \& Madeo F (2011) Polyamines in aging and disease. Aging 3, 716-732.

302. Bardócz S, Grant G, Brown DS, et al. (1993) Polyamines in food - implications for growth and health. J Nutr Biochem $\mathbf{4}$, 66-71.

303. Amendola R, Cervelli M, Fratini E, et al. (2009) Spermine metabolism and anticancer therapy. Curr Cancer Drug Targets $\mathbf{9}, 118-130$.

304. Binh PNT, Soda K, Maruyama C, et al. (2010) Relationship between food polyamines and gross domestic product in association with longevity in Asian countries. Health 2, 1390-1396.

305. Binh PNT, Soda K \& Kawakami M (2011) Mediterranean diet and polyamine intake: possible contribution of increased polyamine intake to inhibition of age-associated disease. Nutr Diet Suppl 3, 1-7.

306. Pucciarelli S, Moreschini B, Micozzi D, et al. (2012) Spermidine and spermine are enriched in whole blood of nona/ centenarians. Rejuvenation Res 15, 590-595.

307. Jia K \& Levine B (2007) Autophagy is required for dietary restriction-mediated life span extension in C. elegans. Autophagy 3, 597-599.

308. Melendez A, Talloczy Z, Seaman M, et al. (2003) Autophagy genes are essential for dauer development and life-span extension in C. elegans. Science 301, 1387-1391.

309. Jenuwein T \& Allis CD (2001) Translating the histone code. Science 293, 1074-1080.

310. Minois N, Carmona-Gutierrez D, Bauer MA, et al. (2012) Spermidine promotes stress resistance in Drosophila melanogaster through autophagy-dependent and -independent pathways. Cell Death Dis 3, e401.

311. LaRocca TJ, Gioscia-Ryan RA, Hearon CM Jr, et al. (2013) The autophagy enhancer spermidine reverses arterial aging. Mech Ageing Dev 134, 314-320.

312. Sarhan S, Knodgen B \& Seiler N (1992) Polyamine deprivation, malnutrition and tumor growth. Anticancer Res 12, 457-466. 
313. Quemener V, Blanchard Y, Chamaillard L, et al. (1994) Polyamine deprivation: a new tool in cancer treatment. Anticancer Res 14, 443-448.

314. Clifford A, Morgan D, Yuspa SH, et al. (1995) Role of ornithine decarboxylase in epidermal tumorigenesis. Cancer Res 55, 1680-1686.

315. Packer L, Witt EH \& Tritschler HJ (1995) $\alpha$-Lipoic acid as a biological antioxidant. Free Radic Biol Med 19, 227-250.

316. Packer L, Tritschler HJ \& Wessel K (1997) Neuroprotection by the metabolic antioxidant $\alpha$-lipoic acid. Free Radic Biol Med 22, 359-378.

317. Packer L, Kraemer K \& Rimbach G (2001) Molecular aspects of lipoic acid in the prevention of diabetes complications. Nutrition 17, 888-895.

318. Bauer JH, Goupil S, Garber GB, et al. (2004) An accelerated assay for the identification of lifespan-extending interventions in Drosophila melanogaster. Proc Natl Acad Sci U S A 101, 12980-12985.

319. Brown MK, Evans JL \& Luo Y (2006) Beneficial effects of natural antioxidants EGCG and $\alpha$-lipoic acid on life span and age-dependent behavioral declines in Caenorhabditis elegans. Pharmacol Biochem Behav 85, 620-628.

320. Benedetti MG, Foster AL, Vantipalli MC, et al. (2008) Compounds that confer thermal stress resistance and extended lifespan. Exp Gerontol 43, 882-891.

321. Farr SA, Price TO, Banks WA, et al. (2012) Effect of $\alpha$-lipoic acid on memory, oxidation, and lifespan in SAMP8 mice. J Alzheimers Dis 32, 447-455.

322. Freisleben HJ, Neeb A, Lehr F, et al. (1997) Influence of selegiline and lipoic acid on the life expectancy of immunosuppressed mice. ArzneimittelForschung 47, 776-780.

323. Arivazhagan P, Juliet P \& Panneerselvam C (2000) Effect of DL- $\alpha$-lipoic acid on the status of lipid peroxidation and antioxidants in aged rats. Pharmacol Res 41, 299-303.

324. Arivazhagan P, Thilakavathy T, Ramanathan K, et al. (2002) Effect of DL- $\alpha$-lipoic acid on the status of lipid peroxidation and protein oxidation in various brain regions of aged rats. J Nutr Biochem 13, 619-624.

325. Hagen TM, Liu J, Lykkesfeldt J, et al. (2002) Feeding acetyl-L-carnitine and lipoic acid to old rats significantly improves metabolic function while decreasing oxidative stress. Proc Natl Acad Sci U S A 99, 1870-1875.
326. Liu J, Killilea DW \& Ames BN (2002) Age-associated mitochondrial oxidative decay: improvement of carnitine acetyltransferase substrate-binding affinity and activity in brain by feeding old rats acetyl-L-carnitine and/or $R$ - $\alpha$ lipoic acid. Proc Natl Acad Sci U S A 99, 1876-1881.

327. Dicter N, Madar Z \& Tirosh O (2002) $\alpha$-Lipoic acid inhibits glycogen synthesis in rat soleus muscle via its oxidative activity and the uncoupling of mitochondria. $J$ Nutr $\mathbf{1 3 2}$, 3001-3006.

328. Bayir H \& Kagan VE (2008) Bench-to-bedside review: mitochondrial injury, oxidative stress and apoptosis there is nothing more practical than a good theory. Crit Care 12, 206 .

329. Nedergaard J, Golozoubova V, Matthias A, et al. (2001) $\mathrm{UCP} 1$, the only protein able to mediate adaptive nonshivering thermogenesis and metabolic inefficiency. Biochim Biophys Acta 1504, 82-106.

330. Shabalina IG, Jacobsson A, Cannon B, et al. (2004) Native UCP1 displays simple competitive kinetics between the regulators purine nucleotides and fatty acids. $J$ Biol Chem 279, 38236-38248.

331. Takahashi H, Bungo Y \& Mikuni K (2011) The aqueous solubility and thermal stability of $\alpha$-lipoic acid are enhanced by cyclodextrin. Biosci Biotechnol Biochem 75, 633-637.

332. Ikuta N, Sugiyama H, Shimosegawa H, et al. (2013) Analysis of the enhanced stability of $R(+)-\alpha$ lipoic acid by the complex formation with cyclodextrins. Int J Mol Sci $\mathbf{1 4}$, 3639-3655.

333. Nikolai S, Huebbe P, Metges CC, et al. (2014) $R$ - $\alpha$ lipoic acid $\gamma$-cyclodextrin complex increases energy expenditure: a 4-month feeding study in mice. Nutrition 30, 228-233.

334. Speakman JR, Talbot DA, Selman C, et al. (2004) Uncoupled and surviving: individual mice with high metabolism have greater mitochondrial uncoupling and live longer. Aging Cell 3, 87-95.

335. Pallauf K, Giller K, Huebbe P, et al. (2013) Nutrition and healthy ageing: calorie restriction or polyphenol-rich "MediterrAsian" diet? Oxid Med Cell Longev 2013, 707421.

336. Chen T, Shen L, Yu J, et al. (2011) Rapamycin and other longevity-promoting compounds enhance the generation of mouse induced pluripotent stem cells. Aging Cell 10, 908-911. 